\title{
C-Terminally Truncated Forms of Tau, But Not Full-Length Tau or Its C-Terminal Fragments, Are Released from Neurons Independently of Cell Death
}

\author{
Daniel Kanmert, ${ }^{1}$ Adam Cantlon, ${ }^{1,2}$ Christina R. Muratore, ${ }^{1}$ Ming Jin, ${ }^{1}$ OTiernan T. 0’Malley, ${ }^{1}$ Gloria Lee, ${ }^{3}$ \\ Tracy L. Young-Pearse, ${ }^{1}$ Dennis J. Selkoe, ${ }^{1}$ and Dominic M. Walsh ${ }^{1}$ \\ ${ }^{1}$ Center for Neurologic Diseases, Brigham and Women's Hospital, Harvard Institutes of Medicine, Boston, Massachusetts 02115, ${ }^{2}$ School of Bimolecular and \\ Biomedical Science, University College Dublin, Dublin 4, Republic of Ireland, and ${ }^{3}$ Department of Internal Medicine, University of Iowa Carver College of \\ Medicine, Iowa City, Iowa 52242
}

Recent evidence suggests that tau aggregation may spread via extracellular release and subsequent uptake by synaptically connected neurons, but little is known about the processes by which tau is released or the molecular forms of extracellular tau. To gain insight into the nature of extracellular tau, we used highly sensitive ELISAs, which, when used in tandem, are capable of differentiating between full-length (FL) tau, mid-region-bearing fragments, and C-terminal (CT) fragments. We applied these assays to the systematic study of the conditioned media of N2a cells, induced pluripotent stem cell-derived human cortical neurons, and primary rat cortical neurons, each of which was carefully assessed for viability. In all three neuronal models, the bulk of extracellular tau was free-floating and unaggregated and $<0.2 \%$ was encapsulated in exosomes. Although most intracellular tau was FL, the majority of extracellular tau was CT truncated and appeared to be released both actively by living neurons and passively by dead cells. In contrast, only a small amount of extracellular tau was aggregation-competent tau (i.e., contained the microtubule-binding regions) and this material appears to be released solely due to a low level of cell death that occurs in all cell culture systems. Importantly, amyloid $\beta$-protein $(\mathrm{A} \beta)$-induced neuronal compromise significantly increased the quantity of all forms of extracellular tau, but the presence of $\mathrm{A} \beta$ before detectable cell compromise did not increase extracellular tau. Collectively, these results suggest that factors that induce neuronal death are likely to be necessary to initiate the extracellular spread of tau aggregation.

Key words: ELISA; exosomes; neurons; secretion; tau

\section{Significance Statement}

Recent studies suggest that the transfer of tau between neurons underlies the characteristic spatiotemporal progression of neurofibrillary pathology. We searched for tau in the conditioned medium of N2a cells, induced pluripotent stem cell-derived human cortical neurons, and primary rat cortical neurons and analyzed the material present using four different tau ELISAs. We demonstrate that the majority of tau released from healthy neurons is C-terminally truncated and lacks the microtubule-binding region (MTBR) thought necessary for self-aggregation. A small amount of MTBR-containing tau is present outside of cells, but this appears to be solely due to cell death. Therefore, if propagation of tau aggregation is mediated by extracellular tau, our findings suggest that neuronal compromise is required to facilitate this process.

\section{Introduction}

The temporal and spatial accumulation of neurofibrillary tangles correlates well with the presentation and progression of symp- toms typical of Alzheimer's disease (AD; Spillantini and Goedert, 2013). Animal (Clavaguera et al., 2009; Frost et al., 2009; de Calignon et al., 2012; Kfoury et al., 2012) and cell culture studies suggest that tau aggregation can propagate from neuron to neu- 
Table 1. Antibodies used, their source, and working concentrations

\begin{tabular}{|c|c|c|c|}
\hline Antigen & Antibody & Source & Concentration \\
\hline Alix & $3 A 9$ & Cell Signaling Technology & $1 \mu \mathrm{g} / \mathrm{ml}$ \\
\hline Flotillin-1 & 18/Flotillin-1 & BD Biosciences & $1 \mu \mathrm{g} / \mathrm{ml}$ \\
\hline HIV glycoprotein 120 & $46-4$ & ATCC & $1 \mu \mathrm{g} / \mathrm{ml}$ \\
\hline $\operatorname{PrP}$ & ICSM35 & D-Gen & $0.5 \mu \mathrm{g} / \mathrm{ml}$ \\
\hline$\beta 3$-tubulin & ab68193 & Abcam & 1:250 dilution \\
\hline$\beta 3$-tubulin & TUJ1 & Covance & $5 \mu \mathrm{g} / \mathrm{ml}$ \\
\hline Tau (aа 6-18) & Tau12 (human) & EMD Millipore & $0.1 \mu \mathrm{g} / \mathrm{ml}^{a}$ \\
\hline Tau (aa 7-13) & HJ9.4 (rodent) & Gift from David Holtzman & $1 \mu \mathrm{g} / \mathrm{ml}^{a}$ \\
\hline Tau (aa 194-198) & BT2 (human + rodent) & Thermo Scientific & $1 \mu \mathrm{g} /\left.\mathrm{ml}\right|^{a, b}$ \\
\hline Tau ( aa 210-241) & Tau5 (human + rodent) & Cell Signaling Technology & $1 \mu \mathrm{g} / \mathrm{ml}^{\mathrm{c}}$ \\
\hline Tau (aa 243-441) & K9JA (human + rodent) & DAKO & $1 \mu \mathrm{g} / \mathrm{ml}^{a, b, c}$ \\
\hline Tau (aа 404-441) & Tau46 (human + rodent) & Cell Signaling Technology & $1 \mu \mathrm{g} / \mathrm{ml}^{a}$ \\
\hline Misfolded tau (residues 7-9 + 313-322) & MC1 & Gift from Peter Davies & $5 \mu \mathrm{g} / \mathrm{ml}^{a}$ \\
\hline
\end{tabular}

Concentrations used for Western blotting: ${ }^{a} 5 \mu \mathrm{g} / \mathrm{ml}$ for IP, ${ }^{b} 2.5 \mu \mathrm{g} / \mathrm{ml}$ for ELISA, ${ }^{c} 5 \mu \mathrm{g} / \mathrm{ml}$ for ELISA.

ron (Frost et al., 2009, Holmes et al., 2014) and there is growing interest in how tau is released and taken up by cells.

Tau does not contain a signal for secretion, yet it is readily detected in the CSF of normal humans (Blennow et al., 1995) and rodents (Barten et al., 2011; Mably et al., 2015) and burgeoning evidence suggests that tau can be detected in the medium of apparently healthy cells (Kim et al., 2010a; Chai et al., 2012; Karch et al., 2012; Plouffe et al., 2012; Simón et al., 2012; Pooler et al., 2013). In addition, the levels of CSF tau are elevated in AD and after acute neuronal injury resulting from stroke, traumatic brain injury, and Creutzfeldt-Jakob disease (Hesse et al., 2000). Therefore, it appears that tau may be released both as a result of neuronal compromise and by specific but poorly described secretion mechanisms (Barten et al., 2011; Chai et al., 2012). Although significant effort has been expended to understand the mechanisms of release, uptake, and propagation, little is known about the molecular forms of tau that are released from neurons.

Until very recently, most studies that measured tau in CSF used immunoassays based on mid-region-directed antibodies incapable of discriminating between full-length (FL) tau and fragments that retain mid-region epitopes. In the few studies to use reliable methodologies, only $\mathrm{N}$-terminal and mid-region fragments of tau were detected in CSF (Johnson et al., 1997; Meredith et al., 2013; Wagshal et al., 2015). The microtubule binding repeat domains (MTBRs) of tau are important for formation of paired helical filaments and contain motifs known to drive aggregation (Barghorn et al., 2004; Goux et al., 2004; Mandelkow and Mandelkow, 2012) and most "seeding" studies have used MTBRcontaining fragments (MTBR-CFs) of tau (Frost et al., 2009; Guo and Lee, 2011; Holmes et al., 2014). Given the established importance of MTBRs for aggregation but their apparent absence in biological fluids, we set out to determine whether FL tau or MTBR-CFs are present in the medium of healthy neurons and whether disease-relevant stresses affect their levels.

Using three different neuronal culture models, we found that tau is released by mechanisms both dependent on and independent of cell death and that the bulk of the released protein is free-floating (soluble) and unaggregated. ELISAs capable of detecting different regions of tau [FL, C-terminal (CT) fragments, and mid-region-containing fragments] revealed that the majority of extracellular tau is CT truncated. Importantly, the extracel-

Correspondence should be addressed to Dominic M. Walsh, Laboratory for Neurodegenerative Research, Center for Neurologic Diseases, Brigham and Women's Hospital, Harvard Institutes of Medicine, 77 Avenue Louis Pasteur, Boston, MA 02115.E-mail: dwalsh3@partners.org.

DOI:10.1523/JNEUROSCI.0387-15.2015

Copyright $\odot 2015$ the authors $\quad 0270-6474 / 15 / 3510852-15 \$ 15.00 / 0$ lular levels of both aggregation-prone MTBR-containing fragments and FL tau are increased when neuronal injury is induced by amyloid $\beta$-protein $(\mathrm{A} \beta)$. These results suggest that cellular compromise is the major mechanism by which MTBR-CFs and FL tau are released from neurons.

\section{Materials and Methods}

Reagents. All chemicals and reagents were purchased from Sigma-Aldrich unless otherwise noted. The antibodies used and their source are described in Table 1 . Synthetic $A \beta_{(1-42)}$ (human sequence) was synthesized and purified using reversed-phase HPLC by Dr. James I. Elliott at Yale University. Peptide mass and purity $(>99 \%)$ were confirmed by reversed-phase HPLC and electrospray/ion trap mass spectrometry. All tissue culture reagents were obtained from Invitrogen and, where appropriate, the medium used to condition cells was centrifuged $(100,000 \times g$ for $18 \mathrm{~h}$ and $4^{\circ} \mathrm{C}$ ) to remove exosomes (Théry et al., 2001).

N2a tissue culture. N2a cells were grown on either 6-well plates or 75 $\mathrm{cm}^{2}$ flasks at $37^{\circ} \mathrm{C}$ in a $5 \% \mathrm{CO}_{2}$ atmosphere in DMEM supplemented with $10 \%$ fetal bovine serum, $5 \%$ L-glutamine, and 5\% penicillin/streptomycin. When cells reached $90 \%$ confluency, the medium was removed and washed once with growth medium. Fresh medium was added and incubated on cells for 6, 24, or $48 \mathrm{~h}$. Cells were lysed in one of two ways: (1) by the addition of Triton X-100 to medium to a final concentration of $1 \%(\mathrm{v} / \mathrm{v})$ and incubated at $37^{\circ} \mathrm{C}$ for $30 \mathrm{~min}$ or (2) by the removal of all the medium and addition of radioimmunoprecipitation assay (RIPA) buffer containing $1 \mathrm{mg} / \mathrm{ml}$ pepstatin $\mathrm{A}, 1 \mathrm{~mm}$ pefabloc, $1 \mathrm{mg} / \mathrm{ml}$ aprotinin, $5 \mathrm{~mm}$ EGTA, and 5 mM EDTA. Conditioned medium (CM) and cell lysates were centrifuged for $10 \mathrm{~min}$ at $200 \times g$ or $16,000 \times g$, respectively, and $4^{\circ} \mathrm{C}$, and used immediately (Fig. $1 \mathrm{~A}$ ).

Induced human cortical neuronal cultures. Induced pluripotent stem cells (iPSCs) were obtained from the UCONN Stem Cell Core and used to produce neurons as described previously (Muratore et al., 2014a). Line YZ1 was produced by injecting iPSCs with retroviral vectors for the reprogramming factors OCT4, SOX2, NANOG, and LIN28 or c-Myc and KLF4 (Zeng, 2010). To ensure a stable chromosome number over time, the NanoString nCounter Human Karyotype Panel CNV CodeSet was used to assay genomic iPSC DNA every $\sim 10$ passages. iPSCs were cultured in iPSC medium and fresh FGF2 (Millipore) was added daily at 10 $\mathrm{ng} / \mathrm{ml}$. Cultures were maintained at $37^{\circ} \mathrm{C}$ and $5 \% \mathrm{CO}_{2}$ and were split as necessary based on colony growth $(\sim 6 \mathrm{~d})$. iPSCs were manually groomed by removing any colonies with irregular borders, spontaneous differentiation, or transparent centers, before splitting. iPSCs were maintained on a mouse embryonic fibroblast feeder layer at 1.7-2.0 $\times 10^{5}$ cells/well of a 6-well plate (Globalstem). For the induction of forebrain cortical neurons, iPSCs were differentiated using an embryoid-body-based protocol (Muratore et al., 2014a). After $24 \mathrm{~d}$ of differentiation, iPSC-derived neuronal aggregates were dissociated to single cells with accutase (Invitrogen) and plated on Matrigel for final differentiation into induced human cortical neurons (iHCNs; 40,000-50,000 cells/well of 96-well plate) using N2/B27 medium supplemented with $10 \mu \mathrm{M}$ ROCK inhibitor 
A

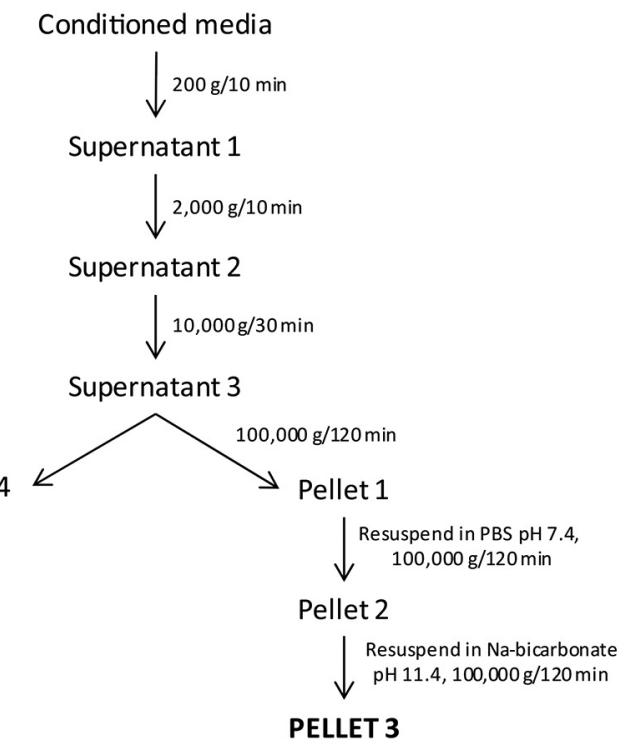

B

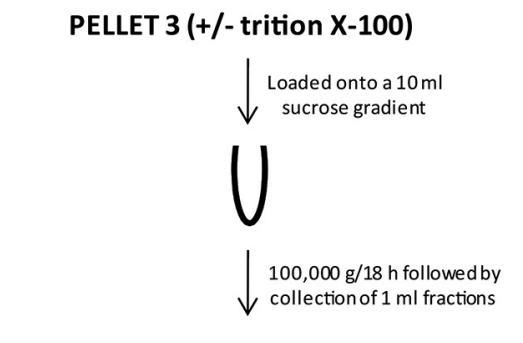

UUUUUUUUU

Sucrose fractions for determination of refractive index + tau ELISA

\author{
Pellets 1-10 resuspended: (1) in 1\% triton X-100 \\ for tau ELISA, (2) in PBS for EM, and (3) in sample \\ buffer for SDS-PAGE
}

Figure 1. Centrifugation conditions used for isolation of exosomes from conditioned medium. $\boldsymbol{A}$, Immediumtely after collection, the medium was subjected to three low-speed spins to remove cells and cellular debris and exosomes were pelleted by centrifugation at $100,000 \times \mathrm{g}$ for $2 \mathrm{~h}$. Pellet 1 was resuspended in PBS and then centrifuged and Pellet 2 was washed in sodium-bicarbonate, pH 11.4, to remove proteins adventitiously associated with the exosomal membranes. B. Crude exosomes (Pellet 3) were treated with or without Triton X-100, loaded onto a 0.25-2.3 $\mathrm{m}$ sucrose gradient, and centrifuged at 100,000 $\times \mathrm{g}$ for $18 \mathrm{~h}$. Ten $1 \mathrm{ml}$ fractions were collected, diluted 1:10 in PBS, centrifuged at 100,000 $\times \mathrm{g}$ for $2 \mathrm{~h}$, and the pellets analyzed.

(StemRD; Muratore et al., 2014a). A full medium change was performed every $3 \mathrm{~d}$ and, on day 45 , postdifferentiation medium was removed and fresh medium was added and incubated on cells for $48 \mathrm{~h}$. For some assays, the medium was pooled across multiple wells of a 96-well plate. Neuronal cultures were characterized by qPCR, Nanostring, and immunostaining followed by confocal microscopy (Muratore et al., 2014a). Maximal expression of tau mRNA is attained between postdifferentiation days 40 and 60 with an approximate ratio of 3:1 3R:4R transcript.

Rat primary hippocampal neuronal cultures. Neurons were prepared and grown essentially as described previously (Minogue et al., 2009, Walsh et al., 2009). Hippocampi were explanted from E18 Sprague Dawley rat pups in Hank's balanced salt solution and dissociated using $0.25 \%$ trypsin (Invitrogen) for $16 \mathrm{~min}$ at $37^{\circ} \mathrm{C}$. Neurons were plated at a density of $3 \times 10^{4}$ cells on the inner 24 wells of poly-D-lysine-coated 48 -well plates and cultivated in neurobasal medium supplemented with $0.5 \mathrm{~mm}$ Glutamax-I (Invitrogen) and B27 with antioxidants (Invitrogen). Seven days after plating, $10 \mu \mathrm{M} 5$-fluoro-2'-deoxyuridine was added to reduce glial proliferation. Cultures were kept in a humidified incubator at $37^{\circ} \mathrm{C}$ and $5 \% \mathrm{CO}_{2}$ and, once per week, half of the medium was replaced with fresh neurobasal medium containing $0.5 \mathrm{~mm}$ Glutamax-I and B27 with antioxidants (Kaech and Banker, 2006). After $21 \mathrm{~d}$ in vitro (DIV), 50\% of the medium was replaced with fresh medium and, after $24 \mathrm{~h}$, the medium and cells were harvested. Medium was processed according to Figure $1 \mathrm{~A}$ and cells were lysed using either $1 \%$ Triton X-100 or RIPA as described above for N2a cells.

Lactate dehydrogenase colorimetric assay. Lactate dehydrogenase $(\mathrm{LDH})$ activity was measured using the Promega cytotoxicity kit in accordance with the manufacturer's instructions. Samples were analyzed in duplicate, standards (bovine pancreatic LDH; 0.004-8 U/ml), and blanks in triplicate. Samples $(50 \mu \mathrm{l})$ were diluted 1:2 with assay buffer and incubated for $30 \mathrm{~min}$ at room temperature. Stop solution $(50 \mu \mathrm{l})$ was added and the absorbance at $490 \mathrm{~nm}$ was measured using a Spectramax plate reader (Molecular Devices). Standard curves were fitted to a fiveparameter logistic function with $1 / \mathrm{Y}^{2}$ weighting, using MasterPlex ReaderFit (MiraiBio). The lower limit of quantification (LLOQ) is defined as the lowest standard point with a signal higher than the average signal for the blank plus 9 SDs and a percent recovery $\geq 100 \pm 20 \%$ and was 0.03 $\mathrm{U} / \mathrm{ml}$. Where appropriate, samples were diluted so that the LDH activity exceeded the LLOQ but was lower than the $8 \mathrm{U} / \mathrm{ml}$ standard.

In certain experiments, the relative viability of primary rat neuron cultures was assessed by staining with propidium iodide and Hoechst
33258 (Aras et al., 2001). Propidium iodide (Life Technologies; 1 mm in sterile MQ water) was added to yield a concentration of $10 \mu \mathrm{M}$ and incubated on cells for $1 \mathrm{~h}$ at $37^{\circ} \mathrm{C}$. At the end of this time, Hoechst (Life Technologies; $1 \mathrm{~mm}$ in DMSO) was added to a concentration of $10 \mu \mathrm{M}$ and cells were incubated for a further $30 \mathrm{~min}$ at $37^{\circ} \mathrm{C}$. Live cultures were then immediately viewed using a Zeiss LSM710 confocal microscope and $10 \times$ objective lens and images were recorded using ZEN Black software. For each experiment, a total of three wells were examined, with one random field per well. The number of Hoechst- and propidium-iodidepositive cells were counted using ImageJ software. Hoechst is a cellpermeable dye and can stain the nuclei of both live and dead cells, whereas propidium iodide is cell impermeant and stains only the nuclei of compromised cells. The percentage cell death was determined using the following formula: $\%$ cell death $=$ (no. of propidium-iodide-stained cells/no. total of Hoechst-stained cells $) \times 100$.

$\beta 3$-tubulin ELISA. Black half-area high binding 96-well plates (Greiner Bio-One) were coated with the anti- $\beta 3$-tubulin $(\beta 3 \mathrm{~T})$ antibody ab68193 (Abcam; diluted 1:250 in TBS, pH 7.4, at $25 \mu \mathrm{l} /$ well) for $1 \mathrm{~h}$ at $37^{\circ} \mathrm{C}$. All remaining steps were conducted at ambient temperature unless otherwise indicated. Wells were washed 5 times with TBS containing $0.05 \%$ Tween 20 (TBS-T) and then blocked with $3 \%(\mathrm{w} / \mathrm{v})$ BSA in TBS for $2 \mathrm{~h}$ with shaking. Thereafter, wells were washed five times with TBS-T. Samples were analyzed in duplicate $(25 \mu \mathrm{l} /$ well $)$, whereas blanks and standards $(7.8-8000 \mathrm{ng} / \mathrm{ml})$ were analyzed in triplicate. The $\beta 3 \mathrm{~T}$ used as a calibrant was from Cytoskeleton. All samples were incubated overnight at $4^{\circ} \mathrm{C}$. The next day, plates were shaken for $2 \mathrm{~h}$ to allow the assay to return to room temperature. Subsequently, $25 \mu \mathrm{l}$ of TUJ1-alkaline phosphatase in TBS-T containing $1 \%(\mathrm{w} / \mathrm{v})$ BSA was added to each well and incubated for $1 \mathrm{~h}$ with shaking. TUJ1 was conjugated to alkaline phosphatase using a Lightning-Link alkaline phosphatase conjugation kit (Innova Biosciences). Wells were washed five times and $50 \mu \mathrm{l}$ of chemiluminescent substrate (Tropix CDP-Star Sapphire II; Applied Biosystems) was added and incubated with shaking for $30 \mathrm{~min}$. Chemiluminescence was measured using a Synery H1 plate reader (Biotek). Standard curves were fitted to a five-parameter logistic function with $1 / \mathrm{Y}^{2}$ weighting, using MasterPlex ReaderFit (MiraiBio). The LLOQ of the assay was $125 \mathrm{ng} / \mathrm{ml}$ (Fig. $2 A$ ). Most CM samples contained little or no $\beta 3 \mathrm{~T}$ and were analyzed without dilution but, where appropriate, $\mathrm{CM}$ and lysates were diluted so that the concentration of $\beta 3 \mathrm{~T}$ exceeded the LLOQ but was lower than the $8000 \mathrm{ng} / \mathrm{ml}$ standard. 
A

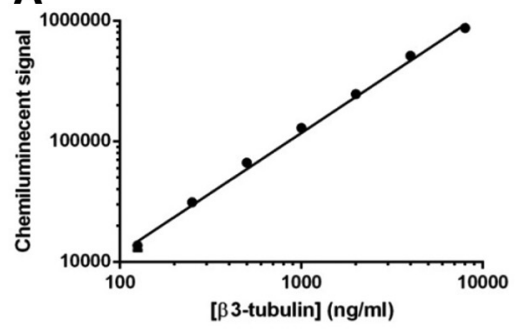

[B3-tubulin] (ng/ml)
B



D

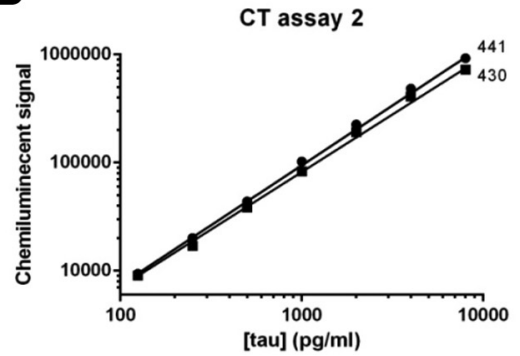

C

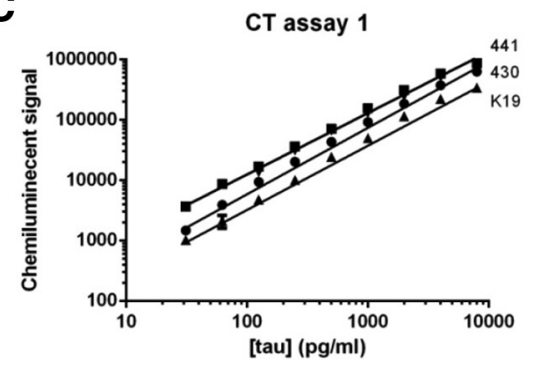

$\mathbf{E}$

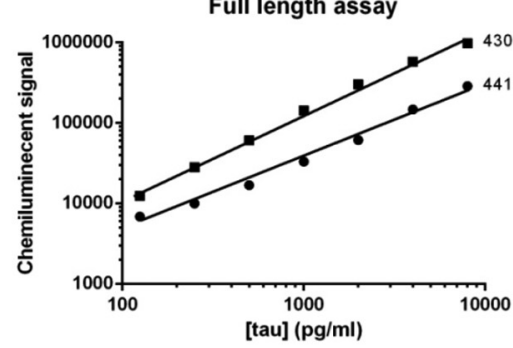

Figure 2. Characterization of $\beta 3$ T and tau ELISAs. A, Calibration curve of $\beta 3$ T standard. The ELISA displays an LLOQ of $\sim 125 \mathrm{pg} / \mathrm{ml}$. B, The BT2-Tau5 ELISA detects FL rodent adult tau 430 ( $\square$ )


D, K9JA-Tau46 ELISA detects FL rodent adult tau ( $\mathbf{\square})$ and human tau $441(\mathbf{)})$ with an LL0Q of $\sim 125 \mathrm{pg} / \mathrm{ml}$, but does not detect K19. E, HJ9.4-Tau46 ELISA detects FL rodent adult tau ( $\mathbf{\square})$ and the Tau12-Tau46 ELISA detects human tau 441 ( $($ ). In each case, the LLOQ is $125 \mathrm{pg} / \mathrm{ml}$. Each data point is the average \pm SD of three replicates. Where error bars are not visible, the SD is smaller than the size of the symbol. See Figure 3 for the location of mAb epitopes and the tau species predicted to be detected by each assay.

Recombinant production of tau proteins. Escherichia coli strain BL21 (DE3) was transformed with expression vectors $\mathrm{pNG} 2 / \mathrm{hTau} 40, \mathrm{pNG} 2 / \mathrm{K} 19$, and pET17b-mTau2310 encoding human tau 441, K19, and rodent tau 430, respectively. The K19 construct contains a total of 98 residues and encompass repeat domains R1, R3, and R4. Proteins were expressed and purified as described previously (Barghorn et al., 2005, O’Dowd et al., 2013). Purity of the proteins was assessed by SDS-PAGE/sliver staining and reversed phaseHPLC. Concentrations were determined using absorbance at $280 \mathrm{~nm}$ and Beer-Lambert's law $\left(\varepsilon_{280}=7575,1490\right.$, and $6085 \mathrm{M}^{-1} \mathrm{~cm}^{-1}$ for human tau 441, K19, and rodent tau 430, respectively).

Mid-region tau ELISA. This assay was performed essentially as described previously (Barten et al., 2011) and the procedure used for mid-region tau ELISA was similar to that used for the $\beta 3$ T ELISA. The anti-tau monoclonal antibody BT2 (Thermo Scientific) at $2.5 \mu \mathrm{g} / \mathrm{ml}$ in TBS was used for capture and Tau 5 conjugated to alkaline phosphatase was used for detection (Fig. 3 ). Samples were analyzed in duplicate, whereas blanks and standards (mouse tau 430 or human tau $441 ; 7.8-8000 \mathrm{pg} / \mathrm{ml}$ ) were analyzed in triplicate. Standard curves were fitted to a five-parameter logistic function with $1 / \mathrm{Y}^{2}$ weighting using MasterPlex ReaderFit (MiraiBio). The LLOQ of the assay was $30 \mathrm{pg} / \mathrm{ml}$ (Fig. 2B) and, where appropriate, samples were diluted so that the concentration of tau exceeded the LLOQ but was lower than the 8000 $\mathrm{pg} / \mathrm{ml}$ standard.

CT tau ELISA 1. CT tau ELISA 1 was performed in the same manner as the mid-region tau assay except that the polyclonal antibody K9JA was used both for capture and detection (Fig. 3). The LLOQ of the assay was $30 \mathrm{pg} / \mathrm{ml}$ (Fig. 2C).

CT tau ELISA 2. This assay was performed in the same manner as the other tau assays except that the polyclonal antibody K9JA was used for capture and the monoclonal antibody Tau46 was used for detection (Fig. 3). The LLOQ of the assay was $125 \mathrm{pg} / \mathrm{ml}$ (Fig. 2D).

FL tau ELISA. This assay was performed in the same manner as the other tau assays. Either monoclonal antibody H9.4 (for rodent tau) or Tau12 (for human tau) was used for capture and the monoclonal antibody Tau46 was used for detection (Fig. 3). The LLOQ of the assay was $125 \mathrm{pg} / \mathrm{ml}$ (Fig. 2E).

All tau assays produced concordant results when samples were serially diluted and displayed excellent recoveries ( $\geq 80 \%$ and $\leq 110 \%$ ) when spiked with recombinant tau.
Immunoprecipitation ELISA. To gain further insight about the aggregation state of extracellular tau, we used the MC1 antibody (which binds misfolded tau) to deplete samples of aberrantly folded tau and measured the concentration of BT2-Tau5 ELISA-detectable tau in samples with and without immunoprecipitation (IP). To control for the efficiency of the IP, we immunoprecipitated replicates of the same samples with BT2. For each IP, 5 $\mu \mathrm{g} / \mathrm{ml} \mathrm{mAb}$ and $7.5 \mu \mathrm{l}$ of protein $\mathrm{G}$ beads (Thermo Scientific) were used. Two rounds of IP were sufficient to achieve maximal depletion with BT2 (data not shown), so each round of IP was performed twice. To remove antibody that could interfere with the ELISA, samples were subsequently incubated with protein $\mathrm{G}$ beads alone. Samples before and after each round of IP were analyzed by BT2-Tau5 ELISA and concentrations were normalized to control samples treated with PBS and beads instead of antibody and beads. Conditioned media and lysate were analyzed in duplicate. Lysates were diluted in $1 \% \mathrm{BSA} / \mathrm{PBS}$ to produce tau concentrations comparable to those of the corresponding CM samples.

Isolation of crude exosomes. N2a cells were cultured in $75 \mathrm{~cm}^{2}$ flasks until $90 \%$ confluent. Cells were washed with $5 \mathrm{ml}$ of growth medium and then incubated in $20 \mathrm{ml}$ of exosome-depleted medium. Primary neurons were conditioned (in 48 -well plates) for $24 \mathrm{~h}$ in $0.3 \mathrm{ml}$ of medium per well and iHCNs were conditioned (in 96-well plates) for $48 \mathrm{~h}$ in $0.1 \mathrm{ml}$ of medium per well. CM was centrifuged at $200 \times g$ and $4^{\circ} \mathrm{C}$ for $10 \mathrm{~min}$ (Fig. $1 A$ ). The upper $95 \%$ of the supernatant (Sup 1) was removed and centrifuged at $2000 \times g$ and $4^{\circ} \mathrm{C}$ for $10 \mathrm{~min}$. Again, the upper $95 \%$ of the supernatant (Sup 2) was removed. This time Sup 2 was centrifuged at $10,000 \times g$ and $4^{\circ} \mathrm{C}$ for $30 \mathrm{~min}$. Supernatant 3 was centrifuged at $100,000 \times g$ and $4^{\circ} \mathrm{C}$ for $2 \mathrm{~h}$. The entire supernatant was poured off and the pellet (Pellet 1 ) resuspended in $30 \mathrm{ml}$ of PBS and exosomes repelleted by centrifugation for $2 \mathrm{~h}$ at $100,000 \times g$ and $4^{\circ} \mathrm{C}$. The PBS wash was poured off. To remove proteins adventitiously associated with the surface of exosomes (Pellet 2), this material was resuspended in $30 \mathrm{ml}$ of 0.1 M sodium bicarbonate, $\mathrm{pH} 11.4$, and the washed exosomes collected by centrifugation at $100,000 \times g$ and $4^{\circ} \mathrm{C}$ for $2 \mathrm{~h}$ (Pellet 3 ). Depending on the volume of CM, we used either an SW28 or SW41Ti rotor (Beckman Coulter) and an Optima L-90K ultracentrifuge (Beckman Coulter).

Sucrose gradient isolation of exosomes. Crude exosomes (Fig. $1 \mathrm{~A}$ ) from each cell model were further fractionated on gradients of $0.25-2.3 \mathrm{M}$ sucrose according to the method of Théry et al. (2001) (Fig. 1B). To 


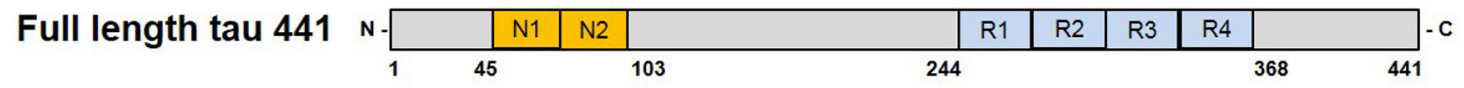

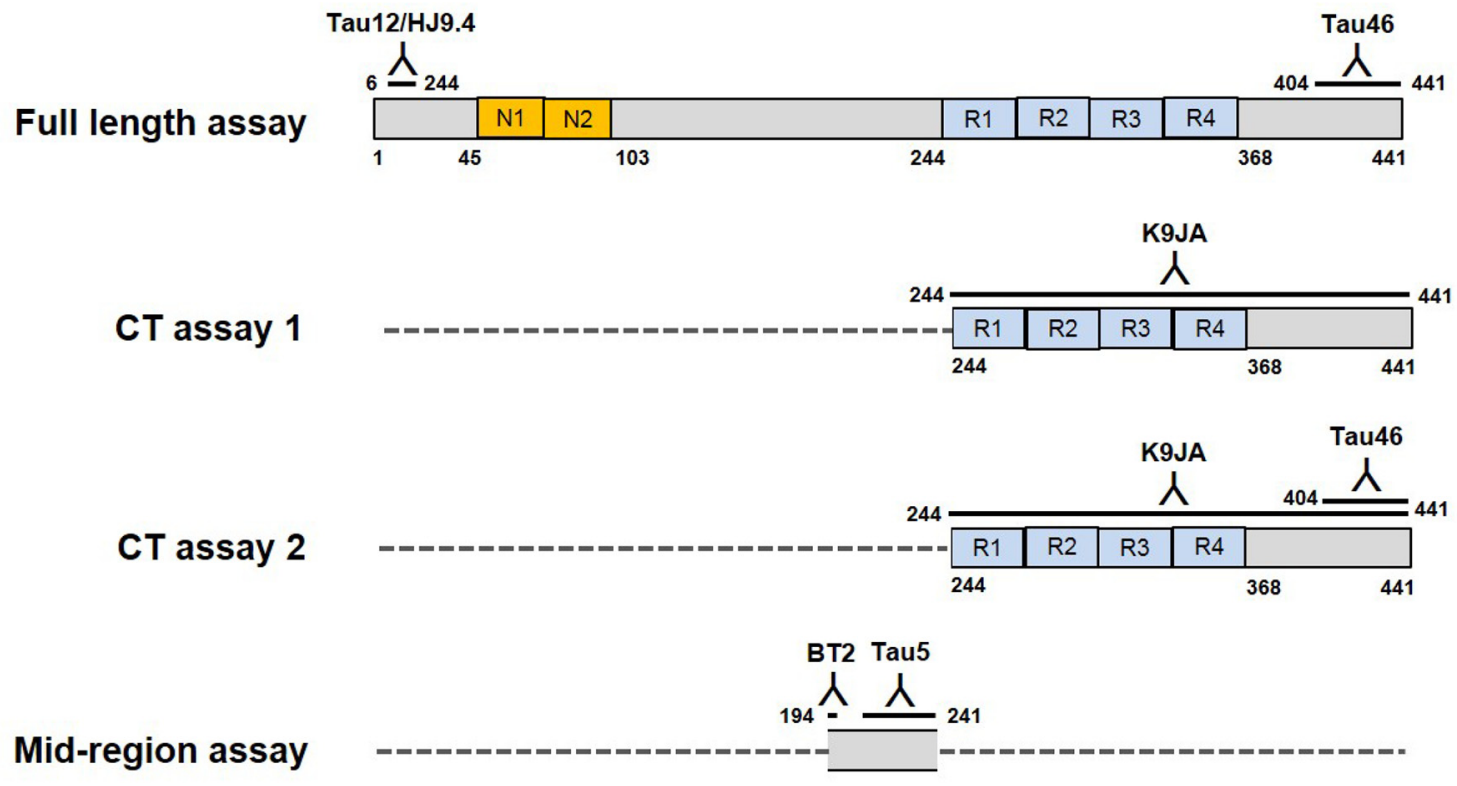

Figure 3. Schematic representation of FL tau and potential fragments detected by ELISA. N-terminal inserts are in yellow and CT repeat domains are in blue. The epitopes for the antibodies used in each ELISA are indicated by a black line and the amino acid numbering of the epitope boundaries is indicated. Sequences of minimal predicted length recognized by a given ELISA are shown in filled boxes and parts of tau fragments of uncertain sequence are indicated with a dashed line.

investigate whether tau was present inside or on the surface of exosomes, Pellet 3 from $400 \mathrm{ml}$ of N2a CM was resuspended in $400 \mu \mathrm{l}$ of PBS and split in two. Each suspension was repelleted by centrifugation at $100,000 \times g$ for $2 \mathrm{~h}$. One pellet was held at $4^{\circ} \mathrm{C}$; the other pellet was resuspended in $20 \mu \mathrm{l}$ of $10 \%(\mathrm{v} / \mathrm{v})$ Triton X-100 in PBS and subjected to two rounds of freeze-thawing using dry ice and a $37^{\circ} \mathrm{C}$ water bath. To ensure completed disruption of exosomes, the suspension was sonicated for $10 \mathrm{~min}$. Thereafter, samples treated with or without Triton X-100 were applied to a $0.25-2.3 \mathrm{~m}$ linear sucrose gradient and centrifuged at $100,000 \times g$ and $4^{\circ} \mathrm{C}$ for $18 \mathrm{~h}$ using an Optima L-90K ultracentrifuge and an SW41Ti rotor (Beckman Coulter). Sucrose gradients were prepared in $12 \mathrm{ml}$ tubes using a peristaltic pump and a mixing chamber with $0.25 \mathrm{M}$ sucrose in $20 \mathrm{~mm}$ HEPES, pH 7.4, in chamber A and $2.3 \mathrm{~m}$ sucrose in 20 mM HEPES, pH 7.4, in chamber B. After centrifugation, $1 \mathrm{ml}$ fractions were collected by sequentially removing samples from the top of the tube (Fig. 1B). Aliquots $(50 \mu \mathrm{l})$ of each fraction were used to measure refractive index. The remainder of the fractions were diluted 1:10 with PBS and then centrifuged at $100,000 \times \mathrm{g}$ and $4^{\circ} \mathrm{C}$ for $2 \mathrm{~h}$ using an Optima L-90K ultracentrifuge and an SW41Ti rotor (Beckman Coulter) to pellet exosomes. Supernatants were poured off and pellets resuspended in $60 \mu \mathrm{l}$ of PBS containing 1\% (v/v) Triton X-100 and 1\% (w/v) BSA. These were then subjected to two freeze-thaw cycles and $10 \mathrm{~min}$ of sonication. For Western blot analysis, a starting volume of $200 \mathrm{ml}$ of $\mathrm{CM}$ was used to isolate exosomes and the final pellet resuspended in $20 \mu \mathrm{l}$ of Laemmli buffer. For electron microscopy (EM), a starting volume of $200 \mathrm{ml}$ of CM was used to isolate exosomes and the final pellet was resuspended in $20 \mu \mathrm{l}$ of PBS. For primary neurons and iHCNs, a starting volume of $35 \mathrm{ml}$ of $\mathrm{CM}$ was used for sucrose-density isolation of exosomes.

Preparation of brain homogenates. Cortical tissue $(200 \mathrm{mg})$ from a male adult C57BL/6J mouse, a 93-year-old cognitively normal woman, and a female Sprague Dawley adult rat were each homogenized in $1 \mathrm{ml}$ of ice-cold RIPA buffer containing $1 \mathrm{mg} / \mathrm{ml}$ aprotinin, $1 \mathrm{mg} / \mathrm{ml}$ pepstatin A, $1 \mathrm{~mm}$ pefabloc, $2 \mathrm{~mm}$ 1,10-phenanthroline, $5 \mathrm{~mm}$ EDTA, and 5 mм EGTA with 20 strokes of a Dounce homogenizer. Homogenates $(1 \mathrm{ml})$ were clarified by centrifugation at $90,000 \times \mathrm{g}$ and $4^{\circ} \mathrm{C}$ for $60 \mathrm{~min}$. The supernatant was removed and protein concentration determined using a BCA kit (Thermo Fisher Scientific). Thereafter, samples were either stored at $-80^{\circ} \mathrm{C}$ or used directly. For dephosphorylation, lysates $(0.2 \mathrm{mg}$ of total protein) were incubated with 40 units of calf intestine alkaline phosphatase (New England Biolabs) at $37^{\circ} \mathrm{C}$ for $1 \mathrm{~h}$.

Western blot. Samples were electrophoresed on 4-12\% polyacrylamide bis-tris gels in MOPS (for tau) or MES (for ALIX-1, Flotillin-1, PrP, and GM1) buffer (Invitrogen) and proteins transferred to nitrocellulose membranes at $400 \mathrm{~mA}$ for $2 \mathrm{~h}$ (Borlikova et al., 2013). Thereafter, membranes were boiled in PBS for $2 \times 90$ s (Ida et al., 1996) and blocked in $1 \%$ $(\mathrm{w} / \mathrm{v})$ BSA in PBS. For exosome experiments, membranes were cut to allow analysis of the same sample for ALIX-1, Flotillin-1, PrP, and GM1 ganglioside. The membranes were incubated overnight at $4^{\circ} \mathrm{C}$ in primary antibody solution, followed by a $6 \times 10 \mathrm{~min}$ wash with PBS-T. The membranes were then incubated in secondary antibody solution for $1 \mathrm{~h}$ at room temperature, followed by a $6 \times 10 \mathrm{~min}$ wash with PBS-T. See Table 1 for details of antibodies and concentrations used. Tau bands were visualized using Licor, whereas ECL Western blotting substrate (Thermo Fisher Scientific) and x-ray films were used for revelation of exosome markers.

A standard containing recombinant versions of all six human tau isoforms was obtained from Sigma-Aldrich and used as a positive control for Western blot experiments involving $\mathrm{iHCN}$ lysates.

Electron microscopy. Sucrose-gradient-isolated exosomes from a starting volume of $200 \mathrm{ml}$ of $\mathrm{N} 2 \mathrm{a}$ CM were resuspended in $10 \mu \mathrm{l}$ of PBS and adsorbed onto 2 formvar-coated copper grids. After $1 \mathrm{~min}$, the grids were washed with water and then counterstained with $1 \%$ uranyl-formate for $1 \mathrm{~min}$. Grids were blotted dry using Whatman filter paper and exosomes were visualized using a 1200EX microscope (JEOL).

Preparation of $1 / 2-t_{\max } A \beta_{(1-42)}$. Half- $t_{\max } \mathrm{A} \beta_{(1-42)}$ was prepared essentially as described previously (Minogue et al., 2009). A $\beta_{(1-42)}$ monomer was isolated by SEC in 10.9 mM HEPES, $\mathrm{pH} 7.8$, and filtered through a $0.22 \mu \mathrm{m}$ filter (Millipore) in a sterile hood. An aliquot of the filtered sample was used for concentration determination by measuring the absorbance at $275 \mathrm{~nm}$ and using the extinction coefficient $1361 \mathrm{M}^{-1} \mathrm{~cm}^{-1}$ (O'Malley et al., 2014). The remainder of the sample was diluted with sterile buffer to $80 \mu \mathrm{M}$ and all further manipulations were performed on 
ice. Thioflavin $\mathrm{T}$ (ThT) was added to a portion of the stock $\mathrm{A} \beta$ solution and aliqouts added into a black 96-well plate (Nunc; Plate 1) and to a second sterile black 96-well plate (Plate 2). The remainder of the A $\beta$ stock solution that did not contain ThT was added to Plate 2 and held on ice for $60 \mathrm{~min}$. Plate 1 was incubated at room temperature (RT) with shaking (700 rpm) and fluorescence was monitored at $20 \mathrm{~min}$ intervals. After 60 min, Plate 2 was also incubated at RT and fluorescence was monitored in the wells containing $\mathrm{A} \beta$ plus ThT. Results from Plate 1 were used to estimate the incubation time required for the samples in Plate 2 to attain half maximal aggregation and the replicates containing ThT in Plate 2 to confirm that the initial phase of aggregation was similar to that observed for samples in Plate 1. $1 / 2 t_{\max }$ samples were then flash frozen on dry ice and stored at $-80^{\circ} \mathrm{C}$ until used for toxicity experiments or for characterization using EM and analytical size exclusion chromatography (aSEC; O’Malley et al., 2014).

Preparation of amyloid $\beta$-derived diffusible ligands. Amyloid $\beta$-derived diffusible ligands (ADDLs) were prepared essentially as described previously (Freir et al., 2011). Hexafluoro-2-propanol (HFIP; $222 \mu \mathrm{l}$ ) was added to $1 \mathrm{mg}$ of $\mathrm{A} \beta_{(1-42)}$ in a $2 \mathrm{ml}$ of low-binding microcentrifuge tube (Eppendorf) to produce a peptide concentration of $1 \mathrm{~mm}$. The solution was incubated at $37^{\circ} \mathrm{C}$ for $1 \mathrm{~h}$ and mixed briefly by vortexing every 10 min. The HFIP was evaporated under a nitrogen stream with rotation of the centrifuge tube to ensure formation of an even film of peptide on the lower walls of the tube. Dried peptide films were stored over desiccant at $-20^{\circ} \mathrm{C}$ for a minimum of $14 \mathrm{~h}$. The peptide film was then dissolved in 40 $\mu \mathrm{l}$ of anhydrous DMSO (Life Technologies) and $5 \mu \mathrm{l}$ of the DMSO mixture was added stepwise to $960 \mu \mathrm{l}$ of F-12 medium (Life Technologies), with vortexing between each addition. The solution was incubated at $4^{\circ} \mathrm{C}$ for $14-16 \mathrm{~h}$ and then centrifuged at $16,000 \times \mathrm{g}$ for $10 \mathrm{~min}$. The upper $95 \%$ of the supernatant was transferred to a new microcentrifuge tube and ADDLs were buffer exchanged into 10.9 mм HEPES, pH 7.8, using a preequilibrated Zeba spin desalting column (7 kDa MWCO; Thermo Fisher Scientific). The concentration of $\mathrm{A} \beta$ oligomers was determined using the extinction coefficient, $\varepsilon_{275}=1361 \mathrm{M}^{-1} \mathrm{~cm}^{-1}$ (O'Malley et al., 2014). After concentration determination, ADDLs were aliquoted, immediately frozen on dry ice, and then stored at $-80^{\circ} \mathrm{C}$. Once thawed, aliquots were characterize by aSEC and EM (O'Malley et al., 2014) or applied to cells.

\section{Results}

Tau is present in the medium of healthy N2a cells at levels slightly but significantly higher than marker cytosolic proteins

Most prior studies that have investigated the extracellular release of tau used transfected cells that overexpress tau (Kim et al., 2010a; Kim et al., 2010b; Chai et al., 2012; Karch et al., 2012; Plouffe et al., 2012; Saman et al., 2012; Simón et al., 2012), whereas we chose to focus on endogenous tau in CM of untransfected cells. Because even strongly expressing cells release only femtomolar levels of tau (Chai et al., 2012) and Western blotting is insufficiently sensitive for the detection of such low levels (Kuiperij and Verbeek, 2012; Petry et al., 2014), we used a well characterized ELISA capable of capturing all isoforms of tau that contain the mid-region residues 194-241 (Figs. 2B, 3; Barten et al., 2011). In preliminary experiments, we examined three neuroblastoma cell lines and found that N2a cells (Fig. 4A) have high levels of viability when grown under standard conditions, as evidenced by release of only low levels of LDH (Fig. 4D), and express appreciable levels of intracellular tau (Fig. 4B). Tau detected in CM could arise from at least three distinct sources: (1) nonspecific leakage due to cellular compromise (Jack et al., 2010), (2) release due to specific but undefined secretory mechanisms (Chai et al., 2012), or (3) release due to membrane turnover and/or vesicle release (Chai et al., 2012; Simón et al., 2012). Therefore, we were careful to compare the levels of tau in CM alongside those of $\mathrm{LDH}$ and $\beta 3 \mathrm{~T}$, two marker cytosolic proteins that are not known to be actively secreted by cells. In addition, to account for the very different intracellular concentrations of tau, $\mathrm{LDH}$, and $\beta 3 \mathrm{~T}$, we measured protein levels or enzymatic activity (in the case of $\mathrm{LDH}$ ) in CM and in lysates and used the values obtained to calculate the percentage of protein in $\mathrm{CM}$ relative to the total amount found in both CM and lysates. Using this approach, we examined the relative levels of tau, $\mathrm{LDH}$, and $\beta 3 \mathrm{~T}$ in medium conditioned by N2a cells for 6, 24, and $48 \mathrm{~h}$. LDH levels were relatively low and remained constant between 6 and $24 \mathrm{~h}$ after medium change and $\beta 3 \mathrm{~T}$ was not detected (Fig. $4 C$ ). However, after $48 \mathrm{~h}, \mathrm{LDH}$ levels were significantly increased and $\beta 3 \mathrm{~T}$ was readily detected. To minimize artifacts arising from cumulative levels of cell death, we conditioned cells for just $24 \mathrm{~h}$. In multiple experiments, the amount of $\mathrm{LDH}$ activity found in medium after $24 \mathrm{~h}$ of conditioning was typically $\leq 1 \%$ of total LDH activity in the respective cell lysate (Fig. $4 C, D$ ). Careful inspection of cells using bright-field microscopy (Fig. $4 A$ ) and trypan blue exclusion (data not shown) indicated that $<1.5 \%$ of cells were dead or damaged and no $\beta 3 \mathrm{~T}$ release was detected. In contrast, even after only $6 \mathrm{~h}$ of incubation, N2a CM was found to contain significantly higher relative amounts of tau than $\mathrm{LDH}$ (Fig. 4C). Importantly, we confirmed that the differences in the detection of the tau, $\mathrm{LDH}$, and $\beta 3 \mathrm{~T}$ proteins in $\mathrm{CM}$ did not result from differences in sensitivity because, when total cell lysate was diluted into the medium, all three assays readily detected $\leq 0.1 \%$ of the respective protein present in lysate (data not shown). Moreover, when $\mathrm{CM}$ was removed from cells and incubated at $37^{\circ} \mathrm{C}$ for $24 \mathrm{~h}$, the levels of tau, $\mathrm{LDH}$, and $\beta 3 \mathrm{~T}$ remained stable (data not shown). There are a number of probable explanations as to why the increase in tau relative to $\mathrm{LDH}$ is more readily detected at early time versus later time point. First, even if tau is released at a constant rate, some may interact with or be taken into cells or be degraded by membrane-bound proteases. Second, with increasing time in culture, there is more cell death and consequently disproportionately more LDH. Third, there may be a homeostatic mechanism that controls the levels of extracellular tau. Whatever the reason that the relative amount of tau to LDH does not increase over time, it is clear that at least a portion of tau detected in the CM of N2a cells is released from healthy cells.

\section{Extracellular tau from N2a cells is largely free-floating and unaggregated}

Next, we investigated whether the tau present in N2a CM was aggregated. We addressed this issue by using a conformationdirected $\mathrm{mAb}$ to capture and immunodeplete $\mathrm{N} 2 \mathrm{a} C \mathrm{CM}$ of reactive tau species and then measure the amount of residual tau that could be detected using our Tau5-BT2 ELISA. In these experiments, each sample was subjected to two rounds of immunodepletion by either MC1 (conformation-directed) or BT2 (mid-region tau unaffected by posttranslational modifications). Excess $\mathrm{mAb}$ was removed by addition of protein $\mathrm{G}$ beads. In two separate experiments, BT2 immunodepletion decreased the Tau5-BT2 ELISA signal in CM by $\sim 100 \%$ and in lysates by $\sim 100 \%$. In contrast, $\mathrm{MC1}$ did not significantly change the amount of tau detected by the Tau5-BT2 ELISA in CM (783 \pm 93 and $729 \pm 73 \mathrm{pg} / \mathrm{ml}$ before vs after IP with MC1) or in lysates $(310 \pm 35 \mathrm{vs} 305 \pm 53 \mathrm{pg}$ of tau/ $\mu \mathrm{g}$ total protein before vs after IP with MC1), whereas MC1 did effectively immunodeplete recombinant aggregated FL tau. To search for aggregates of tau that might not be recognized by MC1, we centrifuged N2a CM under conditions known to pellet tau aggregates $(100,000 \times \mathrm{g}$ for $2 \mathrm{~h}$; Kumar et al., 2014), but again observed no change in the amount of tau in the supernatant (Fig. 5A). The results of the MC1 and 
A

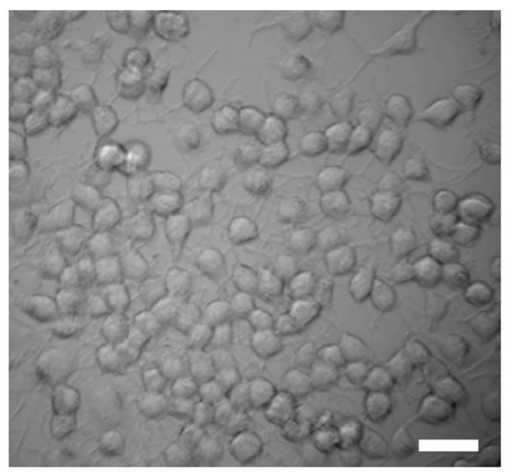

C

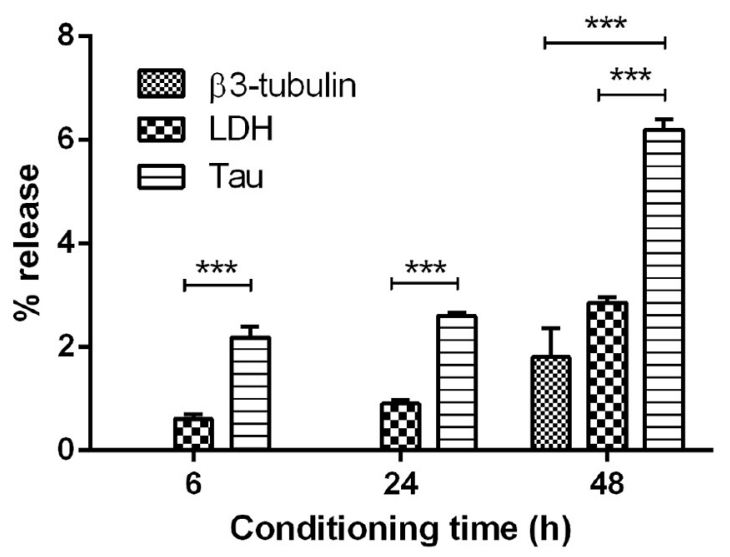

B

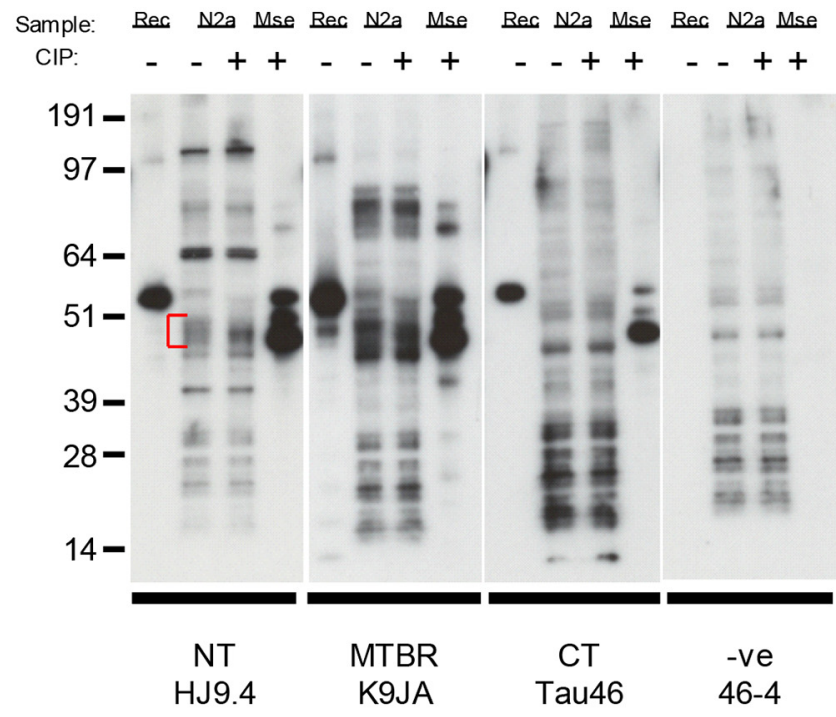

D

\begin{tabular}{|c|c|c|c|}
\hline Expt \# & $\begin{array}{c}\% \text { LDH } \\
\text { release }\end{array}$ & $\begin{array}{c}\% \text { tau } \\
\text { release }\end{array}$ & p-value \\
\hline 1 & $0.9 \pm 0.1$ & $2.6 \pm 0.1$ & $<0.0001$ \\
\hline 2 & $0.08 \pm 0.03$ & $2.4 \pm 0.08$ & $<0.0001$ \\
\hline 3 & $0.2 \pm 0.1$ & $1.4 \pm 0.1$ & $<0.005$ \\
\hline 4 & $1.1 \pm 0.03$ & $1.8 \pm 0.1$ & $<0.005$ \\
\hline 5 & $2.9 \pm 0.2$ & $4.5 \pm 0.1$ & $<0.002$ \\
\hline
\end{tabular}

Figure 4. Healthy N2a cultures express low levels of tau, some of which can be detected in conditioned medium. $A$, Bright-field image of N2a cells after $24 \mathrm{~h}$ of conditioning. Scale bar, $50 \mu \mathrm{m}$. Because the cells were almost confluent and it was difficult to distinguish one cell from another, an edge of lower density is shown. $\boldsymbol{B}$, Western blot analysis of lysates (12.5 $\mu \mathrm{g}$ of total protein/lane) treated with or without calf intestine alkaline phosphatase (CIP) using anti-tau antibodies HJ9.4 (aa 7-13), K9JA (aa 243-441), Tau46 (aa 404 - 441), and the negative control antibody 46-4. Recombinant rodent tau 431 (Rec), $10 \mathrm{ng}$, and (IP-treated mouse brain extract (Mse), $2.5 \mu \mathrm{g}$ of total proteins, were loaded as controls and tau bands are indicated with a bracket. (IP treatment was used as an additional control because dephosphorylated tau tends to migrate a little faster. C, Medium collected from N2a cultures after 6, 24, and $48 \mathrm{~h}$ was analyzed for the presence of tau, LDH, and $\beta 3$ T. Percentage release was calculated according to the following equation: ([analyte in $\mathrm{CM}]) /([$ analyte in $\mathrm{CM}]+$ [analyte in lysate]) $\times 100$. D, Summary of five separate N2a-conditioning experiments reveals that tau is detected in CM at levels disproportionate to cytoplasmic marker proteins. Note that no $\beta 3 \mathrm{~T}$ was detected in medium conditioned for $24 \mathrm{~h}$.

centrifugation experiments indicate that the vast majority of tau present in the CM of healthy N2a cells is not aggregated. In the course of our centrifugation experiments, we probed the pellets to determine whether there were small quantities of pelletable tau the removal of which might not produce a detectable difference between the centrifuged sample and uncentrifuged N2a CM. Indeed, a very small amount of tau (equivalent to $0.1 \%$ of the midregion ELISA signal in the $\mathrm{CM}$ ) was recovered in the pellet and this amount was increased when the pellet was thoroughly disrupted (equivalent to $0.2 \%$ of the mid-region ELISA signal in the $\mathrm{CM}$ ) with detergent and sonication (Fig. 5A: $0.60 \mathrm{vs} 1.18 \mathrm{pg}$ ).

Less than $1 \%$ of extracellular tau in healthy N2a cultures is present in exosomes

Because a prior study reported that tau can be contained in small, extracellular microvesicles known as exosomes (Saman et al., 2012), we used the pellet produced by the $2 \mathrm{~h} 100,000 \times$ g cen- trifugation as the starting point to isolate exosomes and determine whether tau could be detected therein. The $100,000 \times \mathrm{g}$ pellet from $400 \mathrm{ml}$ of $\mathrm{N} 2 \mathrm{a}$ CM was divided in half; one portion was treated with Triton X-100 to lyse any vesicles that might have been present and the other half was gently resuspended in PBS. The two samples were then fractionated on a sucrose gradient (Fig. 1B). Tau was detected in pellets from fractions with a buoyant density $(1.10-1.15 \mathrm{~g} / \mathrm{ml}$ sucrose; Fig. $5 B, \mathbf{\Delta})$ consistent with that reported for exosomes (Théry et al., 2001), whereas tau was not detected in the pellets from the corresponding fraction of the sample that had been pretreated with Triton X-100 (Fig. 5B, +). In the gradient bearing the pellet that had been treated with Triton $\mathrm{X}-100$, tau was found in only the least dense fraction $(\# 1)$, that is, the fraction expected to contain free-floating molecules or molecules from lysed vesicles (Fig. $5 B, \bigcirc$ ). Pelleted fractions from both gradients (i.e., from samples pretreated with and without Triton X-100) were analyzed for the presence of exosome mark- 



C

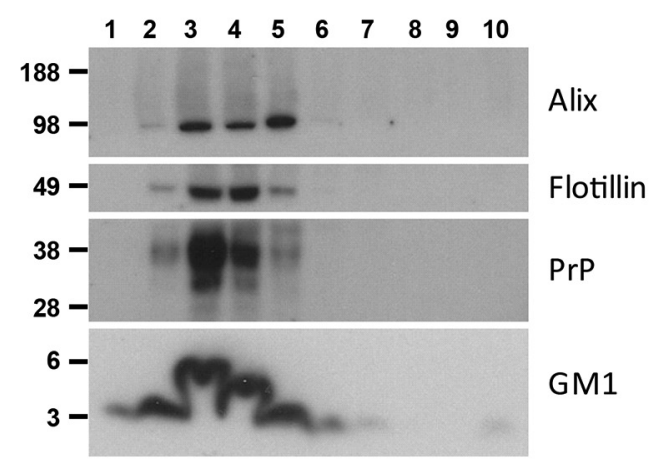

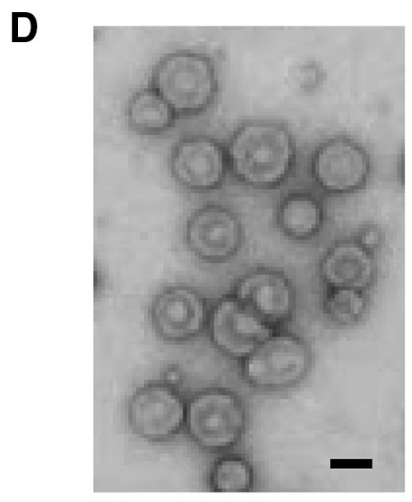

Figure 5. The majority of tau in N2a-conditioned medium is free-floating and unaggregated, but a small amount is present in exosomes. The vast bulk of extracellular tau remains in solution after high-speed centrifugation; nonetheless, a small detectable fraction is pelleted and found inside exosomes. $A$, CM was processed as described in Figure $1 A$ and the $100,000 \times g$ pellet was treated with or without detergent (to disrupt exosomal membranes) before analysis with the BT2-Tau5 ELISA. High-speed centrifugation did not alter the levels of tau detected in N2a CM, but small amounts of tau were detected in the $100,000 \times \mathrm{g}$ pellet. Notably, tau levels were significantly increased in the $100,000 \times \mathrm{g}$ pellets after treatment with Triton X-100. $B$, Crude exosomes isolated from $400 \mathrm{ml}$ of CM (Fig. 1A) were further fractionated by sucrose gradient centrifugation (Fig. 1B). The supernatants and pellets generated from each fraction were analyzed by the BT2-Tau5 ELISA. Tau is detected in the pellets from fractions with intact exosomes $(1.10-1.15 \mathrm{~g} / \mathrm{ml}$ sucrose buoyant density; $\boldsymbol{\Delta})$, whereas no tau can be detected if the exosomes were lysed before fractionation ( + ). Pretreatment of exosomes with Triton X-100 results in tau floating on top of the gradient ( $)$ ). C, Western blot analysis of sucrose gradient fractions produced from a starting volume of $200 \mathrm{ml}$ of $\mathrm{CM}$. The blot was probed with the antibodies to exosomal markers, Alix, Flotllin-1, and PrP, and with choleratoxin-HRP to detect GM1 ganglioside. D, Representative EM image of sucrose gradient fraction 4 . The image is typical of at least three fields from three separate samples. Scale bar, $100 \mathrm{~nm}$. The results in $\boldsymbol{A}-\boldsymbol{D}$ are representative of three experiments.

ers by Western blotting and also examined by EM. As anticipated, exosome markers were not detected in pellets from any sucrose gradient fractions from the Triton X-100-pretreated sample (data not shown). In contrast, the pellets from gradient fractions \#3-5 of the Triton X-100-free sample contained readily detectable levels of the exosome marker proteins Alix-1, Flotillin, and $\mathrm{PrP}$, as well as the lipid GM1, which is abundant in exosomes (Fig. $5 C)$. Moreover, the exosome-positive fractions did not contain detectable amounts of $\beta 3$, Prohibitin, or GRP78 (data not shown). EM examination of the pellets from gradient fractions \#3-5 revealed the presence of $\sim 60$ - $\mu$ m-diameter vesicles typical of exosomes (Théry et al., 2001; Fig. 5D). Therefore, it is apparent that a small amount of the tau released from healthy N2a cells is associated with exosomes.

\section{Free-floating tau is found in conditioned media from iPSC-derived iHCNs}

After the above identification of free-floating, unaggregated tau in N2a CM, we searched for tau in CM from an iHCN line. Cortical neurons were generated from iPSCs from a healthy control (YZ1) using protocols described previously (Muratore et al., 2014a, Muratore et al., 2014b). iHCNs were cultured for $45 \mathrm{~d}$ after differentiation (Fig. 6A) — a stage at which they display appropriate markers of forebrain neurons (Muratore et al., 2014a) and express appreciable levels of tau (Fig. 6B). The neurons were conditioned for $48 \mathrm{~h}$ and CM and lysates collected. In 6 separate experiments, $<5.7 \%$ of total LDH enzymatic activity was present in $\mathrm{CM}$ and no $\beta 3 \mathrm{~T}$ was detected in $\mathrm{CM}$ (Fig. $6 C$ ). The latter finding indicates that, even under conditions when cell compromise is detectable by $\mathrm{LDH}$ release and trypan blue uptake, $\beta 3 \mathrm{~T}$ is not readily released from damaged cells and therefore its measurement is not a useful indicator of low levels (less than $\sim 5 \%$ ) of cell compromise. Consistent with our N2a studies, tau was found in iHCN CM at levels disproportionately higher than LDH (Fig. $6 C)$. Again, we used a combination of MC1 IP and Tau5-BT2 ELISA to search for potential tau aggregates. As before, the conformation-specific $\mathrm{mAb}, \mathrm{MC1}$, did not decrease the amount of tau detected by mid-region-ELISA in iHCN CM $(11.9 \pm 1.4$ and $10.2 \pm 1.5 \mathrm{ng} / \mathrm{ml}$ before vs after IP with MC1) or lysates $(4130 \pm 371$ and $3830 \pm 651 \mathrm{pg}$ of $\mathrm{tau} / \mu \mathrm{g}$ total protein before vs after IP with MC1), whereas BT2 IP completely depleted both $\mathrm{CM}$ and lysate of measurable tau. Again, similar to our N2a study, the amount of tau in iHCN CM was not detectably affected by high-speed centrifugation (Fig. 6D). These results indicate that the overwhelming majority of tau in $\mathrm{HCN}$ CM is free-floating and unaggregated, but, as in N2a CM, small quantities of tau (equivalent to $0.01 \%$ of the mid-region ELISA-detected signal in 
A

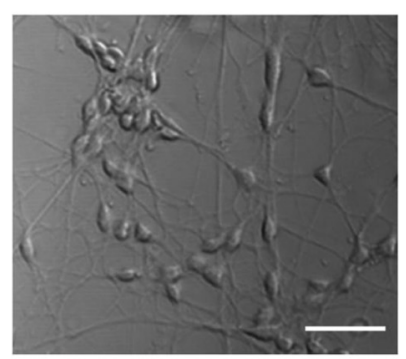

B

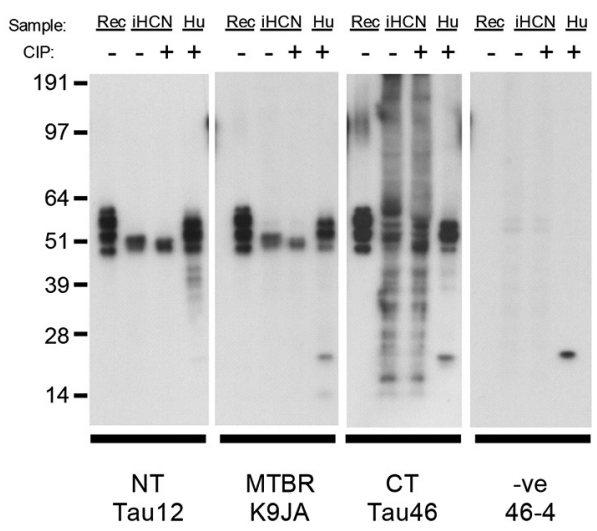

C

\begin{tabular}{|c|c|c|c|}
\hline Expt \# & $\begin{array}{c}\% \text { LDH } \\
\text { release }\end{array}$ & $\begin{array}{c}\% \text { tau } \\
\text { release }\end{array}$ & p-value \\
\hline 1 & $5.1 \pm 0.5$ & $9.6 \pm 1.3$ & $<0.02$ \\
\hline 2 & $4.9 \pm 0.3$ & $6.4 \pm 0.6$ & $\mathrm{~ns}$ \\
\hline 3 & $5.2 \pm 0.5$ & $7.8 \pm 0.2$ & $<0.05$ \\
\hline 4 & $5.7 \pm 0.5$ & $10.1 \pm 0.5$ & $<0.05$ \\
\hline 5 & $3.0 \pm 0.2$ & $4.2 \pm 0.2$ & $<0.05$ \\
\hline 6 & $3.4 \pm 0.1$ & $4.1 \pm 0.2$ & $<0.05$ \\
\hline
\end{tabular}

D

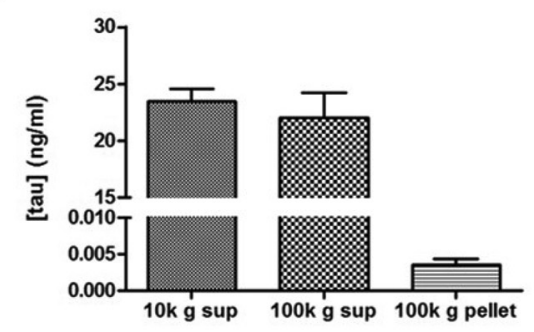

E

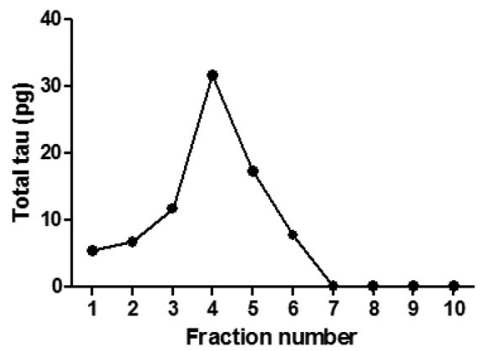

Figure 6. Free-floating tau is readily detected in CM from healthy iHCNs. A, Bright-field image of neurons $45 \mathrm{~d}$ after differentiation. Scale bar, $100 \mu \mathrm{m}$. Because the cells were almost confluent and it was difficult to distinguish one cell from another, an edge of lower density is shown. $\boldsymbol{B}$, Western blot analysis of lysates with or without calf intestine alkaline phosphatase (CIP), $12.5 \mu \mathrm{g}$ of total protein/lane, of $45 \mathrm{~d}$ postdifferentiation neurons (iHCNs) using anti-tau antibodies Tau12 (aa 6-18), K9JA (aa 243-441), Tau46 (aa 404-441), and the negative control antibody 46 - 4. Recombinant versions of all 6 human tau isoforms (Rec), $12 \mathrm{ng}$ of total protein, and (IP-treated human brain extract (Hu), $4 \mu \mathrm{g}$ of total protein, were loaded as controls. C, Medium collected from cultures after $48 \mathrm{~h}$ of conditioning was analyzed for tau, $\mathrm{LDH}$, and $\beta 3 \mathrm{~T}$ and the values presented are expressed relative to the amount of the corresponding protein detected in the lysates of the same cells. In 5 of 6 experiments, tau was released at significantly higher levels than LDH. No $\beta 3$ T was detected in CM. D, CM processed as described in Figure 1A. E, A crude exosomal pellet isolated from $35 \mathrm{ml}$ of $\mathrm{CM}$ was further fractionated on a sucrose gradient according to Figure $1 B$. Tau was found in fractions with sucrose density of $1.10-1.16 \mathrm{~g} / \mathrm{ml}$ (fractions $3-6$ ).

iHCN CM) were recovered in the pellet of a sucrose gradient fraction having a buoyant density typical of exosomes (Fig. 6E).

\section{Free-floating, truncated tau is found in conditioned media of PRNs}

To determine whether expression of a more mature array of tau isoforms influence the amounts and forms of extracellular tau, we examined DIV 21 primary rat hippocampal neurons (PRNs; Fig. $7 A, B)$. Neurons were conditioned for $24 \mathrm{~h}$ and the media and lysates collected. No $\beta 3 \mathrm{~T}$ was detected in $\mathrm{CM}$ and staining with propidium iodide and Hoechst indicated that $<1.5 \%$ of cells were dead (data not shown). In 8 separate experiments, the LDH activity in medium never accounted for $>3.7 \%$ of total LDH activity (Fig. 7C). Consistent with our N2a and iHCN studies, tau was detected in the PRN CM at a level disproportionately higher than LDH (Fig. 7C). Again, IP with the conformation-specific mAb MC1 did not decrease the amount of tau detected by midregion ELISA in PRN CM $(1797 \pm 232$ and $1846 \pm 147 \mathrm{pg} / \mathrm{ml}$ before vs after IP with MC1) or lysates $(2645 \pm 409$ and $2715 \pm$ $357 \mathrm{pg}$ of tau/ $\mu \mathrm{g}$ total protein before vs after IP with MC1), whereas BT2 effectively depleted all detectable tau. As with the $\mathrm{CM}$ from $\mathrm{N} 2 \mathrm{a}$ and iHCN cells, high-speed centrifugation did not detectably lessen the amount of tau in PRN CM (Fig. 7D). These results indicate that the bulk of tau in PRN CM is unaggregated and free-floating, but, as with N2a cells and iHCNs, small quantities of tau (equivalent to $0.01 \%$ of the mid-region ELISAdetected signal in $\mathrm{iHCN} \mathrm{CM}$ ) were detected in buoyant vesicles with a density expected for exosomes (Fig. 7E).

\section{Majority of tau in PRN CM is CT truncated}

Although most prior studies on extracellular tau assumed that the material released was FL, the ELISAs that were used were incapable of differentiating between FL tau and fragments of tau that retain the mid-region epitopes relied upon for detection (Meredith et al., 2013, Pooler et al., 2013). Moreover, previous studies did not specifically identify extracellular CT fragments of tau. We addressed these important issues by developing and validating three new ELISAs (Figs. 2, 3): (1) one that readily detects FL tau but not fragments of tau (Fig. 2E) and assays that detect (2) any form of tau that contains all or part of the $\mathrm{C}$ terminus of tau (Fig. $2 C$ ) or (3) any form of tau with a fully intact C terminus (Fig. 2D). Using these new assays and the aforementioned mid-region ELISA (Fig. 2B), we measured the levels of tau in the CM and lysates of PRNs using the same recombinant FL tau standard for each assay. All four assays measured closely similar levels of tau in lysates (Fig. 8A), but yielded very different values for tau in CM (Fig. $8 B$ ).

The fact that all four assays reported similar levels of tau in lysates strongly suggests that the bulk of tau inside neurons is FL (Fig. 8B). In contrast, in PRN CM, the mid-region assay detected $\sim 10$ times more tau than the FL assay, thus indicating that most extracellular tau is truncated and that FL tau only contributes a small percentage of the total tau found in CM (Fig. 8B). The two CT assays should be capable of detecting both FL tau and any $\mathrm{N}$-terminally truncated fragments that need not extend beyond Gln244 (Fig. 3). Because the CT assays detected approximately twice as much tau in CM as was measured by the FL assay (Fig. 
A

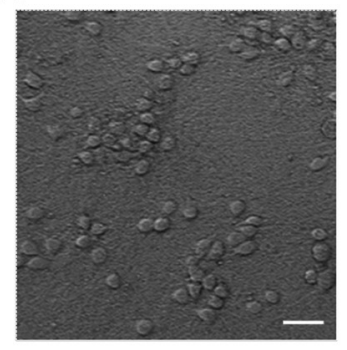

B



C

\begin{tabular}{|c|c|c|c|}
\hline Expt \# & $\begin{array}{c}\% \text { LDH } \\
\text { release }\end{array}$ & $\begin{array}{c}\% \text { tau } \\
\text { release }\end{array}$ & p-value \\
\hline 1 & $2.9 \pm 0.2$ & $6.5 \pm 0.4$ & $<0.02$ \\
\hline 2 & $3.7 \pm 0.2$ & $6.1 \pm 0.1$ & $<0.005$ \\
\hline 3 & $2.1 \pm 0.2$ & $2.7 \pm 0.3$ & ns \\
\hline 4 & $3.0 \pm 0.1$ & $3.0 \pm 0.3$ & ns \\
\hline 5 & $1.0 \pm 0.1$ & $4.2 \pm 0.1$ & $<0.0001$ \\
\hline 6 & $2.4 \pm 0.2$ & $9.3 \pm 0.7$ & $<0.001$ \\
\hline 7 & $2.5 \pm 0.2$ & $5.4 \pm 0.6$ & 0.005 \\
\hline 8 & $1.2 \pm 0.1$ & $1.4 \pm 0.04$ & ns \\
\hline
\end{tabular}

D



E

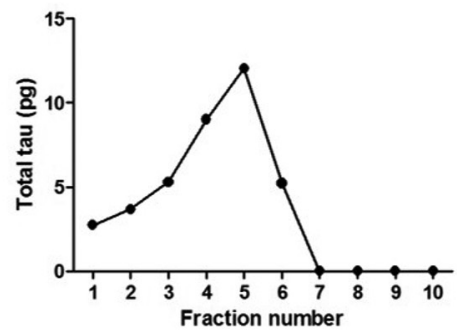

Figure 7. Conditioned medium from healthy primary rat hippocampal neurons contain readily detectable levels of tau. $A$, Bright-field image of DIV 21 neurons. Scale bar, $50 \mu \mathrm{m}$. Because the cells were almost confluent and it was difficult to distinguish one cell from another, an edge of lower density is shown. $\boldsymbol{B}$, Lysates $(50 \mu \mathrm{g})$ of PRNs were treated with or without calf intestine alkaline phosphatase (CIP) and used for Western blotting with the anti-tau antibodies HJ9.4 (aa 7-13), BT2 (aa 194-198), K9JA (aa 243-441), Tau46 (aa 404-441), and the negative control antibody 46-4. Recombinant rodent tau 431 (Rec), $10 \mathrm{ng}$, and (IP-treated rat brain extract (Rat), $5 \mu \mathrm{g}$, were loaded as controls. C, Medium collected from DIV 21 neurons after $24 \mathrm{~h}$ of conditioning was analyzed for the presence of tau, LDH, and $\beta 3$ T. Tau was detected at levels disproportionate to the release of LDH and, in 5 of 8 experiments, the levels were significantly higher than LDH ( $p<0.02$ ). NS indicates that the levels of tau and LDH are not significantly different. $\beta 3$ T was not detected in the CM from any experiment. $D$, CM processed as described in Figure $1 A$. E, Crude exosomal pellet isolated from $35 \mathrm{ml}$ of $\mathrm{CM}$ was further fractionated on a sucrose gradient according to Figure $1 B$. Tau was found in fractions with sucrose density $1.11-1.16 \mathrm{~g} / \mathrm{ml}$, fractions $3-6$, consistent with exosomes.

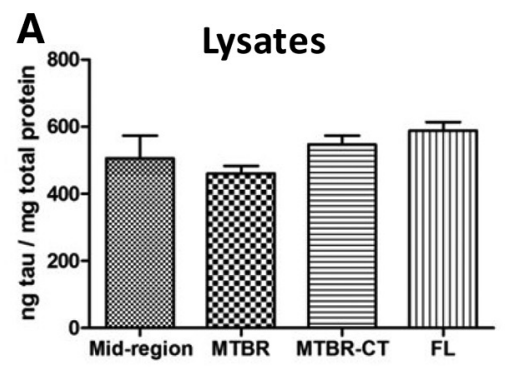

B

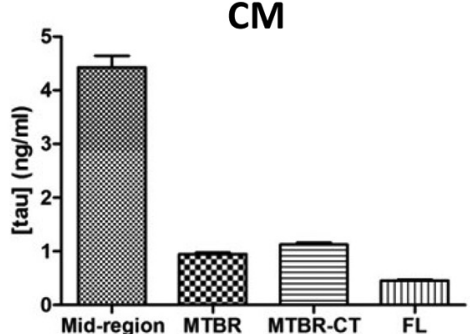

C

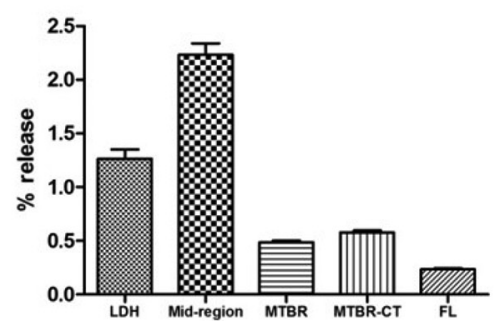

D

Full length assay

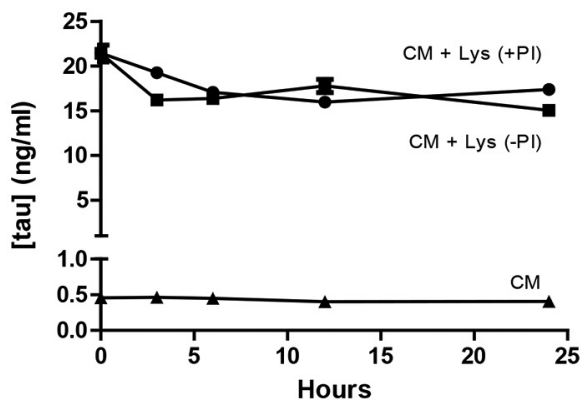

$\mathbf{E}$

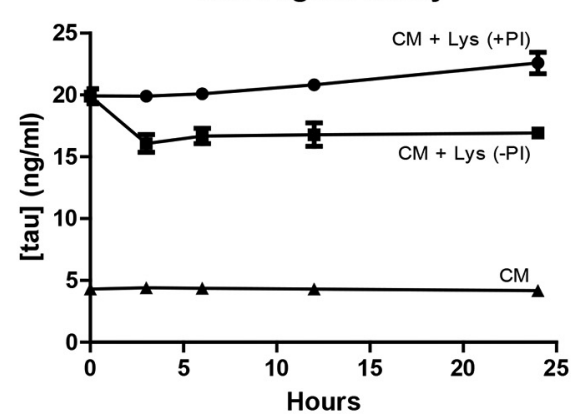

Figure 8. The majority of extracellular tau is $\mathrm{CT}$ truncated. $\boldsymbol{A}$, Mid-region, $\mathrm{CT} 1$, $\mathrm{CT} 2$, and FL tau detected in CM from DIV 21 PRNs. $\boldsymbol{B}$, Mid-region, $\mathrm{CT1}$, $\mathrm{CT2}$, and FL tau detected in lysate from DIV 21 PRNs. C, Percentage release of LDH and mid-region, CT1, CT2, and FL tau from DIV 21 PRNs. Percentage release was calculated according to the following equation: ([analyte in CM])/([analyte in $\mathrm{CM}]+$ [analyte in lysate] $) \times 100 . \boldsymbol{D}, \boldsymbol{E}$, Lysate from PRN $(\sim 2 \mu \mathrm{g}$ tau/ml) with and without protease inhibitors was diluted 1:100 into PRN CM. A portion was snap frozen on dryice and the remainder aliquoted and incubated at $37^{\circ} \mathrm{C}$ for $3,6,12$, and $24 \mathrm{~h}$. Tau detected by $\mathrm{FL}(\boldsymbol{D})$ and mid-region ELISAs $(\boldsymbol{E})$ remained relatively constant over time, indicating little or no degradation of tau. 
$8 B$ ), we conclude that $\sim 50 \%$ of the CT assay signal is attributable to FL tau and $50 \%$ to forms of tau that contain an intact $\mathrm{C}$ terminus but are $\mathrm{N}$-terminally truncated. The amount of tau detected in PRN CM with the mid-region assay was $\sim 4-5$ times greater than the amount of tau detected by the CT assays. This suggests that $\sim 75 \%$ of the tau detected by the mid-region assay must contain all or most of the Tau5 epitope (210-241), but lacks sequence extending beyond $\mathrm{G} \ln 244$. The $\mathrm{N}$ terminus of the BT2 epitope extends to Arg194 and, although we can only speculate as to how far N-terminally the fragments detected by the midregion assay may extend (Fig. 3), recent studies on human CSF (Meredith et al., 2013; Wagshal et al., 2015) and iPS neurons (Bright et al., 2015) indicate that this material is likely to be highly heterogeneous with regard to $\mathrm{N}$ termini.

Because we had shown for each of the three neuronal systems that at least a portion of the tau in CM detected by the mid-region assay was present at levels higher than the percentage of released $\mathrm{LDH}$ (and therefore apparently independent of neuronal compromise), we investigated whether the relative amount of tau species detected by our other tau assays also exceeded that attributable to cell leakage. Importantly, the relative amount of extracellular tau measured by the FL and CT ELISAs in CM was lower than that of $\mathrm{LDH}$ in the same CM, suggesting that FL and CT fragments of tau were unlikely to be released by mechanisms independent of neuronal compromise. The difference in the ratio of extracellular to intracellular tau measured using the midregion assay versus the other tau assays (Fig. $8 \mathrm{C}$ ) further suggests that mid-region-containing fragments are specifically released from neurons by a process independent of cell compromise/death.

To investigate whether mid-region-containing fragments were generated by extracellular cleavage of FL tau, we conducted time course experiments in which PRN CM or PRN CM spiked with PRN lysate was incubated at $37^{\circ} \mathrm{C}$ with and without protease inhibitors and samples were analyzed using the FL tau (HJ9.4Tau46) ELISA. The amount of FL tau detected in PRN CM was low and did not change upon incubation regardless of the presence of protease inhibitors. Neuronal lysates contain abundant FL tau (Fig. 8A) so that the addition of a small amount of lysate was sufficient to yield a FL tau concentration of $\sim 20 \mathrm{ng} / \mathrm{ml}$; that is, a level $\sim 40$-fold greater than the concentration of endogenous FL tau in PRN CM (cf. Fig. $8 A, B, D$ ). As with endogenous tau, the levels of the exogenous (lysate spike) FL tau remained constant throughout the $24 \mathrm{~h}$ incubation (Fig. 8D). As an additional control, we also measured tau using the mid-region (BT2-Tau5) ELISA. The amount of tau detected by the mid-region assay was $\sim 8-9 \%$ lower in samples without protease inhibitors, but did not change over time (Fig. $8 E$ ). Together, these results indicate that PRN CM contains little or no proteolytic activities capable of cleaving FL tau and that CT truncated tau fragments are likely to be produced inside neurons and then released.

\section{$\mathrm{A} \boldsymbol{\beta}$-induced cell death leads to the release of multiple forms of tau from PRN}

Given that certain assembly forms of the $\mathrm{A} \beta$ can influence aspects of tau biology and that $A \beta$-induced changes in tau are believed to be critically involved in AD pathogenesis (Spires-Jones and Hyman, 2014), we investigated whether $\mathrm{A} \beta$ can influence the levels and forms of tau released from neurons. We treated primary rat neurons with a partially aggregated preparation of $\mathrm{A} \beta_{(1-42)}$ that contained both amyloid fibrils and $\mathrm{A} \beta$ monomer (Fig. $9 A$ ). This preparation is referred to as $1 / 2 t_{\max }$ because it is produced by incubating $\mathrm{A} \beta$ monomer for a period that yields half the maximal level of thioflavin T fluorescence (Fig. 9A; Minogue et al., 2009;
O'Malley et al., 2014). In 5 separate experiments, $20 \mu \mathrm{M} 1 / 2 t_{\max }$ caused a time-dependent decrease in neuronal viability such that, from day 5 , the level of LDH in media was significantly elevated compared with the vehicle control (Fig. 9B, $p>0.005$ ). When the same CM was analyzed using the BT2-Tau5 mid-region ELISA, the relative increase in extracellular tau signal (Fig. 9C) was similar to the increase seen in LDH (Fig. 9B), suggesting that the increase in tau was attributable to $\mathrm{A} \beta$-induced neuronal compromise. Sister cultures treated with excitotoxic levels of glutamate (as a positive control) also evidenced a direct correspondence between the relative levels of tau and $\mathrm{LDH}$ detected in medium (cf. Fig. 9B,C). Given that these time course experiments (Fig. $9 C$ ) allowed us to analyze medium from cells treated with $\mathrm{A} \beta$ both before and after induction of cell leakage/death, it is clear that the addition of $\mathrm{A} \beta$ to the cultures per se did not alter the levels of tau detected by the mid-region ELISA. Therefore, treatment of neurons with a preparation of $A \beta$ that over time induced toxicity did not cause any discernible change in extracellular tau before loss of membrane integrity.

It is possible that only certain forms of tau may be specifically altered by $\mathrm{A} \beta$ and that these changes are not detected using the mid-region BT2-Tau5 ELISA. In this context, we also measured tau in CM using our FL and CT ELISAs. In two separate experiments, both CT ELISAs revealed a time-dependent increase in extracellular tau from neurons treated with $\mathrm{A} \beta$, whereas the level of tau in CM from vehicle-treated PRNs actually fell modestly (Fig. 9D,E). The levels of CT-tau in CM from PRNs treated with glutamate were elevated from day 1 compared with vehicle- or $\mathrm{A} \beta$-treated cells and remained high throughout the $7 \mathrm{~d}$ experiment. Therefore, the changes seen with the mid-region and CT ELISAs were broadly similar (Fig. 9C-E). Remarkably, the levels of FL tau fell in PRNs treated with vehicle or glutamate (Fig. 9F), whereas the levels of FL tau were increased on days 5 and 7 after $\mathrm{A} \beta$ treatment $(p<0.02)$. In summary, time-dependent increases in extracellular tau were only evident in cultures with injured neurons and both glutamate and $A \beta$ caused an increase in tau as measured using the mid-region and CT assays. Notably A $\beta$, but not glutamate, caused an increase in extracellular FL tau. Therefore, $A \beta$ treatment that resulted in cell leakage/death caused a similar time-dependent increase in tau measured using four different ELISAs. The reason that the overt damage induced by glutamate did not increase extracellular FL tau but $\mathrm{A} \beta$ did hints that the mechanisms by which neurons die may influence the release of certain forms of tau (e.g., FL tau) and merits further investigation.

Because several different forms of $A \beta$ have been shown to compromise normal neuronal activity and this can be accomplished at much lower concentrations than is required to induce cell death (Wang et al., 2002; Freir et al., 2011), we also investigated whether low concentrations of synaptotoxic $A \beta$ could alter the amount or forms of extracellular tau. For this, we used an $A \beta$ preparation known as ADDLs (Lambert et al., 1998; Wang et al., 2002; Hepler et al., 2006; Freir et al., 2011). Aliquots of preprepared ADDLs, which when applied to hippocampal slices at a concentration of $500 \mathrm{nM}$ blocked LTP (data not shown), were thawed on ice and added directly to neurons or characterized by SEC and EM (Fig. 9G). At intervals, CM was removed and analyzed for LDH and tau. Consistent with prior experiments (Fig. 9B), LDH was increased in CM of cells treated with $20 \mu \mathrm{M}$ glutamate versus the vehicle control at all time points studied (data not shown). Also in keeping with our other experiments (Fig. 9C), treatment with glutamate caused a timedependent increase in tau detected by the mid-region assay (Fig. 9H) and an increase in CT1-detected tau was evident throughout the $7 \mathrm{~d}$ 
A

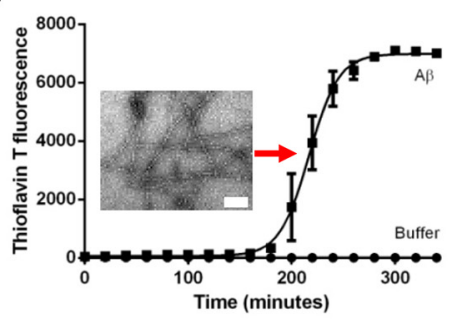

D

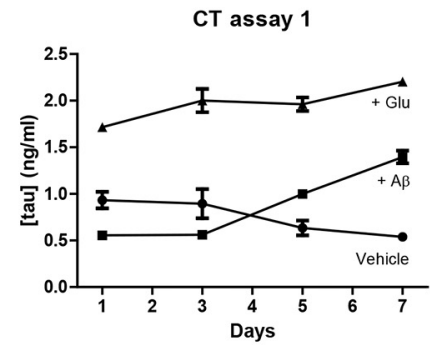

G

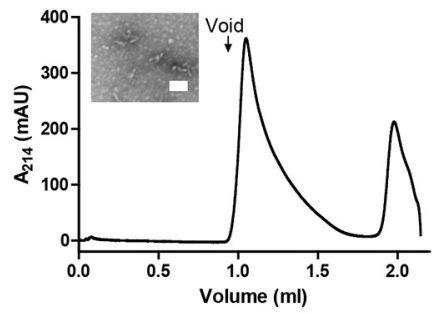

B

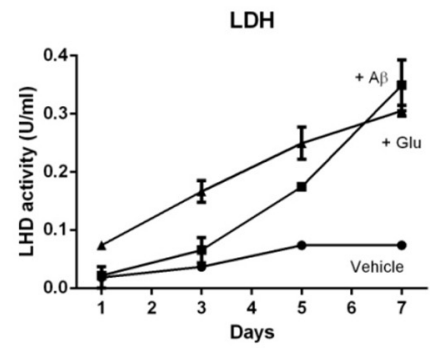

E



H

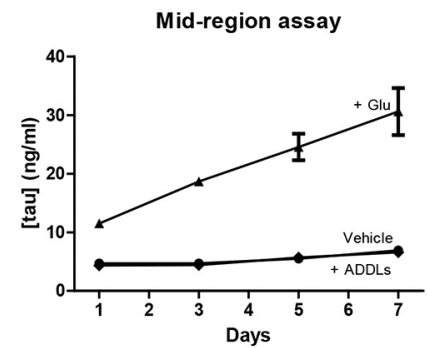

C

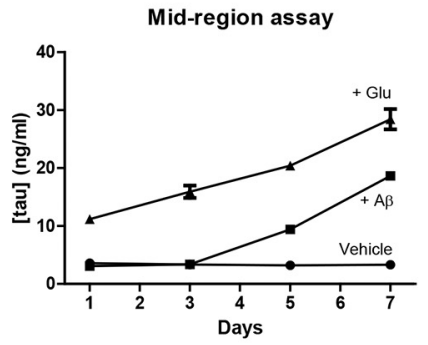

$\mathbf{F}$

Full length assay

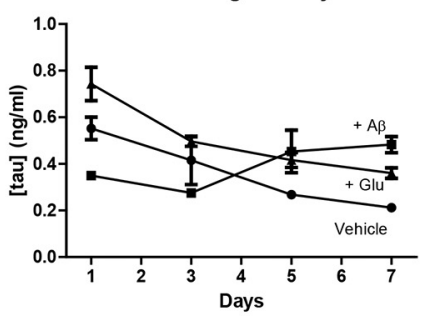

CT assay 1



Figure 9. A $\beta$-induced cell compromise increases the amount of truncated tau in medium from primary rat hippocampal neurons. $A$, Aggregation of SEC-isolated $A \beta$ (1- 42$)$ was followed using a continuous thioflavin T (ThT)-binding assay and fluorescence values are expressed in relative fluorescence units and plotted versus time. The $1 / 2 t_{\text {max }}$ point at which sample was collected and used for toxicity experiments is indicated by the red arrow and the inset shows a negatively stained transmission EM of $1 / 2 t_{\max } A \beta_{(1-42)}$. Scale bar, $100 \mathrm{~nm}$. B, LDH activity in PRN CM after $1,3,5$, and $7 \mathrm{~d}$ of treatment with $20 \mu \mathrm{m} 1 / 2 t_{\max } A \beta_{(1-42) ;}(\square), 20 \mu \mathrm{m}$ glutamate $(\mathbf{\Delta})$, and vehicle (10.9 mm HEPES, pH 7.8; $\left.\boldsymbol{O}\right)$. Differences in LDH levels between the vehicle control and test conditions were compared on each day using the Student's $t$ test. Glutamate caused an elevation in tau on all days $(p<0.01)$, whereas $A \beta$ treatment increased tau only on days 5 and 7 ( $p<0.01$ ). Insets show MAP2-stained neurons after $7 \mathrm{~d}$ of treatment with $20 \mu \mathrm{M} 1 / 2 t_{\max } A \beta_{(1-42)}$ and $10.9 \mathrm{~mm} \mathrm{HEPES}$, pH 7.8. C, Tau detected by BT2-Tau5 (mid-region) ELISA in PRN CM after 1, 3, 5, and $7 \mathrm{~d}$ of treatment with $20 \mu \mathrm{m} 1 / 2 t_{\max } A \beta_{(1-42) ;}(\square), 20 \mu \mathrm{m}$ glutamate $(\mathbf{A})$, and vehicle (10.9 mM HEPES, pH 7.8; $)$ ). Differences in tau concentration between the vehicle control and test conditions were compared on each day using the Student's $t$ test. Glutamate treatment $(\mathbf{\Delta})$ caused a significant elevation in tau on all days $(p<0.01)$, whereas $A \beta_{(1-42)}(\square)$ caused a significant increase only on days 5 and $7(p<0.01)$. D, E, Tau detected by the CT1 (K9JA-K9JA; $\boldsymbol{D})$ and CT2 (K9JA-Tau46; $\boldsymbol{E})$ ELISAs evinced elevation on days $1,3,5$, and 7 in medium from cells treated with glutamate $(\mathbf{\Delta} ; p<0.05)$ and on days 5 and 7 when cells were treated with $A \beta_{(1-42)}(\mathbb{Q} ; p<0.02)$. $\boldsymbol{F}$, Tau detected in PRN CM by the FL (HJ9.4-Tau46) ELISA showed no difference between cultures treated with vehicle or glutamate on any day, whereas the levels of FL tau were elevated in CM from neurons treated with $A \beta_{(1-42)}(\square)$ compared with vehicle (10.9 mm HEPES, pH 7.8; $\left.\mathbf{O}\right)$ on day 7 ( $\left.p<0.05\right)$. $\mathbf{G}, A D D L s$ were prepared as described in the Materials and Methods and characterized by aSEC (void volume indicated with an arrow) and negative contrast EM. Scale bar, $100 \mathrm{~nm}$. $\boldsymbol{H}$, Tau detected by BT2-Tau5 (mid-region) ELISA in PRN CM after 1, 3, 5, and $7 \mathrm{~d}$ of treatment with $0.5 \mu \mathrm{m}$ ADDLs $(\boldsymbol{\nabla}), 20 \mu \mathrm{m}$ glutamate ( $\boldsymbol{\Delta}$ ), and vehicle (10.9 mu HEPES, pH 7.8; $\mathbf{0})$. Differences in tau concentration between the vehicle control and test conditions were compared on each day using the Student's $t$ test. Glutamate treatment $(\boldsymbol{\Delta})$ caused a significant elevation in tau on all days $(p<0.05)$, whereas ADDLs $(\checkmark)$ did not cause a significant increase on any day ( $p>0.05$ ). I, Tau detected by the (T1 (K9JA-K9JA) ELISA in PRN CM after 1, 3, 5, and $7 \mathrm{~d}$ of treatment with $0.5 \mu \mathrm{m}$ ADDLs ( $\bullet$ ), $20 \mu \mathrm{m}$ glutamate $(\mathbf{\Delta})$, and vehicle (10.9 mm HEPES, pH 7.8; ). Glutamate treatment $(\mathbf{A})$ caused a significant elevation in tau on all days $(p<0.01)$, whereas ADDLs $(\boldsymbol{})$ did not cause a significant increase on any day $(p>0.05)$. The data shown are derived from a minimum of six wells per treatment.

study. In contrast, $500 \mathrm{~nm}$ ADDLs did not increase extracellular levels of tau measured using either mid-region or CT1 ELISAs (Fig. $9 H, I)$. Therefore, as with the results from the $1 / 2 t_{\max }$ studies, application of bioactive $\mathrm{A} \beta$ (in this case, $\mathrm{ADDLs}$ ) did not alter extracellular tau in the absence of overt neuronal compromise.

\section{Discussion}

The possibility that aggregation of certain proteins linked to neurodegeneration may propagate in a manner analogous to that proposed for the prion protein has drawn much attention in recent years (Spires-Jones and Hyman, 2014). However, although there is clear evidence that extracellular application of exogenous tau aggregates to cultured cells or injection of aggregates into rodent brain can induce aggregation of endogenous tau, little is known about the fundamental processes involved and how they might be initiated in the human brain. A spread mechanism for a supposedly cytosolic protein such as tau must involve at least four phases: (1) release of tau from donor neurons, (2) aggregation of tau (this could occur before or after point 1), (3) uptake of tau into certain recipient neurons, and (4) induction of aggregation of tau in the recipient cells. Understanding the molecular forms of tau released and the mechanisms by which this is achieved are of obvious interest.

Several prior studies investigated the release of tau in various cell culture systems. Most used tau overexpression models (Kim et al., 2010a; Kim et al., 2010b; Chai et al., 2012; Plouffe et al., 
2012; Simón et al., 2012), a few used untransfected cells (Chai et al., 2012; Karch et al., 2012; Bright et al., 2015), and two analyzed tau in medium from immature primary cortical rodent neurons (Karch et al., 2012, Pooler et al., 2013). All of these studies suggest that the tau detected in cell medium is released by an unconventional secretion mechanism (Kim et al., 2010a, b; Chai et al., 2012; Karch et al., 2012; Plouffe et al., 2012; Saman et al., 2012; Simón et al., 2012). Some groups reported that tau is released from cells in exosomes (Saman et al., 2012, Simón et al., 2012), whereas others found no evidence for tau in exosomes (Karch et al., 2012). Importantly, only one prior study rigorously controlled for the level of cell death (Chai et al., 2012), but these investigators used transfected HEK cells and measured tau using a mid-region ELISA incapable of distinguishing between FL tau and mid-regioncontaining fragments of tau (Chai et al., 2012).

Here, we report a series of systematic experiments that involved three distinct neuronal model systems; the use of highly sensitive ELISAs that differentiate between FL tau, mid-regionbearing fragments, and CT fragments; and careful assessment of cell viability. To determine whether the amount of tau in CM was higher than that attributable to cell rupture, we measured the levels of two marker cytosolic proteins ( $\mathrm{LDH}$ and $\beta 3 \mathrm{~T}$ ) that are not actively secreted from cells and counted dead cells using trypan blue and/or propidium iodide/Hoechst. To control for differences in the expression of tau, $\mathrm{LDH}$, and $\beta 3 \mathrm{~T}$, we measured protein levels or enzymatic activity in CM and in lysates and used the values obtained to calculate the percentage of protein in $\mathrm{CM}$ according to the following equation: ([analyte in $\mathrm{CM}]) /([$ analyte in $\mathrm{CM}]+$ [analyte in lysate] $) \times 100$. To ensure reproducibility, at least five replicate experiments were conducted for each neuronal cell model studied. In agreement with other reports, we found that the level of extracellular tau (measured using our mid-region ELISA) was higher than that which could be attributed to the low level of cell death evident in our cultures. Only a tiny portion of this released material was found in exosomes. Similar results were obtained in $\mathrm{N} 2 \mathrm{a}$ cells, iHCNs, and mature PRNs. In contrast to the mid-region-detected material, the low signals for tau in PRN CM measured using assays specific for FL-tau- or CT-containing fragments are fully explainable by the low level of cell death evident in our (and all) cell cultures. In preliminary experiments, similar results were obtained when comparing mid-region, FLdetected tau, and CT-detected tau in CM and lysates of N2a cells, iHCNs, and mature human fetal neurons (data not shown). Therefore, in four distinct neuronal culture systems (N2a cells, iHCNs, PRNs, and human fetal neurons), different forms of tau are released from neurons by different processes. CT-truncated forms of tau are released by mechanisms that are both dependent and independent of cell death and FL and CT fragments of tau appear to be released only upon cell death.

The specific and sensitive detection of tau in biofluids is not trivial (Portelius et al., 2008; Kuiperij and Verbeek, 2012); up to six spliced isoforms can be present and tau is known to undergo multiple after translational modifications, including heterogeneous proteolysis (Lee and Leugers, 2012). In this study, we chose to investigate the molecular identity of extracellular tau using highly specific and sensitive ELISAs, which, when used in tandem, yielded significant information about the nature of tau in the medium of cultured neurons. The assays that we developed allow for the detection of very low levels of the protein regardless of aggregation and/or phosphorylation state; the ELISA signals are appropriately responsive to dilution and are abolished when samples are immunodepleted with relevant anti-tau mAbs. In future studies, it will be important to develop orthogonal meth- ods to define more precisely the species detected by both our mid-region and CT ELISAs. Nonetheless, from our analysis, it is already clear that $\mathrm{N}$-terminal fragments that are detected in the $\mathrm{CM}$ of healthy neurons by our mid-region assay share similar antigenic profiles as the heterogeneous mid-domain and $\mathrm{N}$-terminal tau fragments recently described in human CSF (Meredith et al., 2013, Wagshal et al., 2015), whereas the FL and CT species released as a result of cell death are distinct.

Low levels of cell death among CNS neurons is inevitable (Spalding et al., 2013) and tau is a highly abundant protein (Lee and Leugers, 2012). Therefore, one would anticipate that, even in healthy brains, a small amount of MTBR-containing tau will be released as a consequence of cell death. The initial reports of the detection of extracellular tau in cultures of apparently healthy cells raised the hope that therapeutically inhibiting the active release of tau might attenuate the spread of tau aggregates in the brain (Mohamed et al., 2013). However, this strategy would be of use only if the forms of tau released were capable of aggregation. Therefore, our finding that only non-MTBR-containing forms of tau are actively released from healthy neurons suggests that there would be no benefit in inhibiting this process. Indeed, given the apparent specificity for the release from healthy neurons of midregion-containing tau lacking the MTBRs, it is possible that these species may serve some normal extracellular function and that inhibition of their release could be detrimental (Mably et al., 2015). Similarly, it is conceivable that mid-region-containing fragments of tau could influence signal transduction pathways to affect neurodegeneration in ways yet to be discovered.

Because it is impossible to prevent the low level of neuronal death that occurs naturally, and many events can heighten such neuronal compromise, our demonstration that small amounts of MTBR-containing forms of tau are released during neuronal death have implications for understanding human tauopathies and developing therapies. If the "pathogenic spread" hypothesis, which has been so elegantly demonstrated in rodent models (Clavaguera et al., 2009; de Calignon et al., 2012) and cell culture (Frost et al., 2009; Kfoury et al., 2012; Holmes et al., 2014), has any relevance to human tauopathies, then the central question arises as to what is the first site of aggregation (intracellular or extracellular) and how is tau released. Our data suggest that aggregation-competent tau is released only upon cell compromise. However, none of the culture systems that we studied produced intraneuronal aggregates, so our work is presumably relevant only to the release of unaggregated forms of tau, some of which could later aggregate after release. Our study deliberately focuses on physiological forms of tau; however, further studies will be required to determine whether aggregates of tau are only released passively or if there are specific active release processes that can be targeted therapeutically. Furthermore, a rigorous analysis of the phosphorylation status of extracellular tau and the forms of tau found in exosomes is also merited.

With regard to the other self-aggregating protein in $\mathrm{AD}$, addition of aggregated $A \beta$ to PRNs induced cell compromise starting between days 3 and 5 after treatment and all 4 ELISAs recorded an elevation in tau coincident with the onset of neuronal death. Similar to what has been described in the CSF of APP transgenic mice (Maia et al., 2013; Mably et al., 2015), extracellular tau did not change in the early phase of $\mathrm{A} \beta$ toxicity, but increased only when cell loss became evident. Moreover, treatment of PRNs with ADDLs at a concentration that impairs synaptic plasticity but does not induce cell death did not alter the amount or form of extracellular tau. Therefore, if $A \beta$ is the trigger that stimulates the initial release from neurons of aggregation- 
competent (i.e., MTBR-containing) tau in $\mathrm{AD}$ and models thereof, it would appear to require specific injury of certain neurons. Regardless of whether tau is released passively as a result of cell death or via active processes, the therapeutic use of antibodies that target aggregated tau or MTBR-containing aggregationcompetent forms of tau appear to offer great promise $(\mathrm{Gu}$ and Sigurdsson, 2011; Castillo-Carranza et al., 2014; Holmes and Diamond, 2014). An extension of the work described here to elucidate further the molecular identities of extracellular tau should facilitate the better design of efficacious immunotherapy approaches.

\section{References}

Aras MA, Hartnett KA, Aizenman E (2001) Assessment of cell viability in primary neuronal cultures. in: current protocols in neuroscience. Curr Protoc Neurosci Chapter 7:Unit 7.18. CrossRef Medline

Barghorn S, Davies P, Mandelkow E (2004) Tau paired helical filaments from Alzheimer's disease brain and assembled in vitro are based on $\beta$-structure in the core domain. Biochemistry 43:1694-1703. CrossRef Medline

Barghorn S, Biernat J, Mandelkow E (2005) Purification of recombinant tau protein and preparation of Alzheimer-paired helical filaments in vitro. In: Amyloid proteins, Vol 299 (Sigurdsson E, ed), pp 35-51. New York: Humana.

Barten DM, Cadelina GW, Hoque N, DeCarr LB, Guss VL, Yang L, Sankaranarayanan S, Wes PD, Flynn ME, Meredith JE, Ahlijanian MK, Albright CF (2011) Tau transgenic mice as models for cerebrospinal fluid tau biomarkers. J Alzheimers Dis 24:127-141. CrossRef Medline

Blennow K, Wallin A, Agren H, Spenger C, Siegfried J, Vanmechelen E (1995) Tau protein in cerebrospinal fluid: a biochemical marker for axonal degeneration in Alzheimer disease? Mol Chem Neuropathol 26:231245. CrossRef Medline

Borlikova GG, Trejo M, Mably AJ, Mc Donald JM, Sala Frigerio C, Regan CM, Murphy KJ, Masliah E, Walsh DM (2013) Alzheimer brain-derived amyloid $\beta$-protein impairs synaptic remodeling and memory consolidation. Neurobiol Aging 34:1315-1327. CrossRef Medline

Bright J, Hussain S, Dang V, Wright S, Cooper B, Byun T, Ramos C, Singh A, Parry G, Stagliano N, Griswold-Prenner I (2015) Human secreted tau increases amyloid-beta production. Neurobiol Aging 36:693-709. CrossRef Medline

Castillo-Carranza DL, Sengupta U, Guerrero-Muñoz MJ, Lasagna-Reeves CA, Gerson JE, Singh G, Estes DM, Barrett AD, Dineley KT, Jackson GR, Kayed R (2014) Passive immunization with tau oligomer monoclonal antibody reverses tauopathy phenotypes without affecting hyperphosphorylated neurofibrillary tangles. J Neurosci 34:4260-4272. CrossRef Medline

Chai X, Dage JL, Citron M (2012) Constitutive secretion of tau protein by an unconventional mechanism. Neurobiol Dis 48:356-366. CrossRef Medline

Clavaguera F, Bolmont T, Crowther R, Abramowski D, Frank S, Probst A, Fraser G, Stalder AK, Beibel M, Staufenbiel M, Jucker M, Goedert M, Tolnay M (2009) Transmission and spreading of tauopathy in transgenic mouse brain. Nat Cell Biol 11:909-913. CrossRef Medline

de Calignon A, Polydoro M, Suárez-Calvet M, William C, Adamowicz DH, Kopeikina KJ, Pitstick R, Sahara N, Ashe KH, Carlson GA, Spires-Jones TL, Hyman BT (2012) Propagation of tau pathology in a model of early Alzheimer's disease. Neuron 73:685-697. CrossRef Medline

Holmes BB, Diamond MI (2014) Prion-like Properties of tau proteie importance of extracellular tau as a therapeutic target. J Biol Chem 289: 19855-19861. CrossRef Medline

Freir DB, Nicoll AJ, Klyubin I, Panico S, Mc Donald JM, Risse E, Asante EA, Farrow MA, Sessions RB, Saibil HR, Clarke AR, Rowan MJ, Walsh DM, Collinge J (2011) Interaction between prion protein and toxic amyloid [beta] assemblies can be therapeutically targeted at multiple sites. Nat Commun 2:336. CrossRef Medline

Frost B, Jacks RL, Diamond MI (2009) Propagation of tau misfolding from the outside to the inside of a cell. J Biol Chem 284:12845-12852. CrossRef Medline

Goux WJ, Kopplin L, Nguyen AD, Leak K, Rutkofsky M, Shanmuganandam VD, Sharma D, Inouye H, Kirschner DA (2004) The formation of straight and twisted filaments from short tau peptides. J Biol Chem 279: 26868-26875. CrossRef Medline

Gu J, Sigurdsson EM (2011) Immunotherapy for tauopathies. J Mol Neurosci 45:690-695. CrossRef Medline

Guo JL, Lee VM (2011) Seeding of normal tau by pathological tau conformers drives pathogenesis of Alzheimer-like tangles. J Biol Chem 286:1531715331. CrossRef Medline

Hepler RW, Grimm KM, Nahas DD, Breese R, Dodson EC, Acton P, Keller PM, Yeager M, Wang H, Shughrue P, Kinney G, Joyce JG (2006) Solution state characterization of amyloid $\beta$-derived diffusible ligands. Biochemistry 45:15157-15167. CrossRef Medline

Hesse C, Rosengren L, Vanmechelen E, Vanderstichele H, Jensen C, Davidsson P, Blennow K (2000) Cerebrospinal fluid markers for Alzheimer's disease evaluated after acute ischemic stroke. J Alzheimers Dis 2:199-206. Medline

Holmes BB, Furman JL, Mahan TE, Yamasaki TR, Mirbaha H, Eades WC, Belaygorod L, Cairns NJ, Holtzman DM, Diamond MI (2014) Proteopathic tau seeding predicts tauopathy in vivo. Proc Natl Acad Sci U S A 111:E4376-E4385. CrossRef Medline

Ida N, Hartmann T, Pantel J, Schröder J, Zerfass R, Förstl H, Sandbrink R, Masters CL, Beyreuther K (1996) Analysis of heterogeneous $\beta$ A4 peptides in human cerebrospinal fluid and blood by a newly developed sensitive Western blot assay. J Biol Chem 271:22908-22914. CrossRef Medline

Jack CR Jr, Knopman DS, Jagust WJ, Shaw LM, Aisen PS, Weiner MW, Petersen RC, Trojanowski JQ (2010) Hypothetical model of dynamic biomarkers of the Alzheimer's pathological cascade. Lancet Neurol 9:119-128. CrossRef Medline

Johnson GV, Seubert P, Cox TM, Motter R, Brown JP, Galasko D (1997) The $\tau$ protein in human cerebrospinal fluid in Alzheimer's disease consists of proteolytically derived fragments. J Neurochem 68:430-433. Medline

Kaech S, Banker G (2006) Culturing hippocampal neurons. Nat Protoc 1:2406-2415. CrossRef Medline

Karch CM, Jeng AT, Goate AM (2012) Extracellular tau levels are influenced by variability in tau that is associated with tauopathies. J Biol Chem 287: 42751-42762. CrossRef Medline

Kfoury N, Holmes BB, Jiang H, Holtzman DM, Diamond MI (2012) Transcellular propagation of tau aggregation by fibrillar species. J Biol Chem 287:19440-19451. CrossRef Medline

Kim W, Lee S, Hall GF (2010a) Secretion of human tau fragments resembling CSF-tau in Alzheimer's disease is modulated by the presence of the exon 2 insert. FEBS Lett 584:3085-3088. CrossRef Medline

Kim W, Lee S, Jung C, Ahmed A, Lee G, Hall GF (2010b) Interneuronal transfer of human tau between Lamprey central neurons in situ. J Alzheimers Dis 19:647-664. Medline

Kuiperij HB, Verbeek MM (2012) Detection of tau forms in CSF requires sensitive techniques. Neurobiol Aging 33:1841. CrossRef

Kumar S, Tepper K, Kaniyappan S, Biernat J, Wegmann S, Mandelkow EM, Müller DJ, Mandelkow E (2014) Stages and conformations of the tau repeat domain during aggregation and its effect on neuronal toxicity. J Biol Chem 289:20318-20332. CrossRef Medline

Lambert MP, Barlow AK, Chromy BA, Edwards C, Freed R, Liosatos M, Morgan TE, Rozovsky I, Trommer B, Viola KL, Wals P, Zhang C, Finch CE, Krafft GA, Klein WL (1998) Diffusible, nonfibrillar ligands derived from $A \beta 1-42$ are potent central nervous system neurotoxins. Proc Natl Acad Sci U S A 95:6448-6453. CrossRef Medline

Lee G, Leugers CJ (2012) Tau and tauopathies. In: Progress in molecular biology and translational science, Vol 107 (David BT, ed), pp 263-293. New York: Academic.

Mably AJ, Kanmert D, Mc Donald JM, Liu W, Caldarone BJ, Lemere CA, O’Nuallain B, Kosik KS, Walsh DM (2015) Tau immunization: a cautionary tale? Neurobiol Aging 36:1316-1332. CrossRef Medline

Maia LF, Kaeser SA, Reichwald J, Hruscha M, Martus P, Staufenbiel M, Jucker $M$ (2013) Changes in amyloid- $\beta$ and tau in the cerebrospinal fluid of transgenic mice overexpressing amyloid precursor protein. Sci Trans Med 5:194re192. CrossRef Medline

Mandelkow EM, Mandelkow E (2012) Biochemistry and cell biology of tau protein in neurofibrillary degeneration. Cold Spring Harb Perspect Med 2:a006247. Medline

Meredith JE Jr, Sankaranarayanan S, Guss V, Lanzetti AJ, Berisha F, Neely RJ, Slemmon JR, Portelius E, Zetterberg H, Blennow K, Soares H, Ahlijanian 
M, Albright CF (2013) Characterization of novel CSF tau and ptau biomarkers for Alzheimer's disease. PLoS One 8:e76523. CrossRef Medline

Minogue AM, Stubbs AK, Frigerio CS, Boland B, Fadeeva JV, Tang J, Selkoe DJ, Walsh DM (2009) $\gamma$-secretase processing of APLP1 leads to the production of a p3-like peptide that does not aggregate and is not toxic to neurons. Brain Res 1262:89-99. CrossRef Medline

Mohamed NV, Herrou T, Plouffe V, Piperno N, Leclerc N (2013) Spreading of tau pathology in Alzheimer's disease by cell-to-cell transmission. Eur J Neurosci 37:1939-1948. CrossRef Medline

Muratore CR, Rice HC, Srikanth P, Callahan DG, Shin T, Benjamin LN, Walsh DM, Selkoe DJ, Young-Pearse TL (2014a) The familial Alzheimer's disease APPV717I mutation alters APP processing and Tau expression in iPSC-derived neurons. Hum Mol Gen 23:3523-3536. CrossRef Medline

Muratore CR, Srikanth P, Callahan DG, Young-Pearse TL (2014b) Comparison and optimization of hiPSC forebrain cortical differentiation protocols. PLoS One 9:e105807. CrossRef Medline

O'Dowd ST, Ardah MT, Johansson P, Lomakin A, Benedek GB, Roberts KA, Cummins G, El Agnaf OM, Svensson J, Zetterberg H, Lynch T, Walsh DM (2013) The ELISA-measured increase in cerebrospinal fluid tau that discriminates Alzheimer's disease from other neurodegenerative disorders is not attributable to differential recognition of tau assembly forms. J Alzheimers Dis 33:923-928. Medline

O’Malley TT, Oktaviani NA, Zhang D, Lomakin A, O'Nuallain B, Linse S, Benedek GB, Rowan MJ, Mulder FA, Walsh DM (2014) Abeta dimers differ from monomers in structural propensity, aggregation paths and population of synaptotoxic assemblies. Biochem J 461:413-426. CrossRef Medline

Petry FR, Pelletier J, Bretteville A, Morin F, Calon F, Hébert SS, Whittington RA, Planel E (2014) Specificity of anti-tau antibodies when analyzing mice models of Alzheimer's disease: problems and solutions. PLoS One 9:e94251. CrossRef Medline

Plouffe V, Mohamed NV, Rivest-McGraw J, Bertrand J, Lauzon M, Leclerc N (2012) Hyperphosphorylation and cleavage at D421 enhance tau secretion. PLoS One 7:e36873. CrossRef Medline

Pooler AM, Phillips EC, Lau DH, Noble W, Hanger DP (2013) Physiological release of endogenous tau is stimulated by neuronal activity. EMBO Rep 14:389-394. CrossRef Medline

Portelius E, Hansson SF, Tran AJ, Zetterberg H, Grognet P, Vanmechelen E, Höglund K, Brinkmalm G, Westman-Brinkmalm A, Nordhoff E, Blen- now K, Gobom J (2008) Characterization of tau in cerebrospinal fluid using mass spectrometry. J Proteome Res 7:2114-2120. CrossRef Medline

Saman S, Kim W, Raya M, Visnick Y, Miro S, Saman S, Jackson B, McKee AC, Alvarez VE, Lee NC, Hall GF (2012) Exosome-associated tau is secreted in tauopathy models and is selectively phosphorylated in cerebrospinal fluid in early Alzheimer disease. J Biol Chem 287:3842-3849. CrossRef Medline

Simón D, García-García E, Royo F, Falcón-Pérez JM, Avila J (2012) Proteostasis of tau. Tau overexpression results in its secretion via membrane vesicles. FEBS Lett 586:47-54. CrossRef Medline

Spalding KL, Bergmann O, Alkass K, Bernard S, Salehpour M, Huttner HB, Boström E, Westerlund I, Vial C, Buchholz BA, Possnert G, Mash DC, Druid H, Frisén J (2013) Dynamics of hippocampal neurogenesis in adult humans. Cell 153:1219-1227. CrossRef Medline

Spillantini MG, Goedert M (2013) Tau pathology and neurodegeneration. Lancet Neurol 12:609-622. CrossRef Medline

Spires-Jones TL, Hyman BT (2014) The intersection of amyloid beta and tau at synapses in Alzheimer's disease. Neuron 82:756-771. CrossRef Medline

Théry C, Amigorena S, Raposo G, Clayton A (2001) Isolation and characterization of exosomes from cell culture supernatants and biological fluids. Curr Protoc Cell Biol Chapter 3:Unit 3.22. CrossRef Medline

Wagshal D, Sankaranarayanan S, Guss V, Hall T, Berisha F, Lobach I, Karydas A, Voltarelli L, Scherling C, Heuer H, Tartaglia MC, Miller Z, Coppola G, Ahlijanian M, Soares H, Kramer JH, Rabinovici GD, Rosen HJ, Miller BL, Meredith J, Boxer AL (2015) Divergent CSF $\tau$ alterations in two common tauopathies: Alzheimer's disease and progressive supranuclear palsy. J Neurol Neurosurg Psychiatry 86:244-250. Medline

Walsh DM, Thulin E, Minogue AM, Gustavsson N, Pang E, Teplow DB, Linse $S$ (2009) A facile method for expression and purification of the Alzheimer's disease-associated amyloid $\beta$-peptide. FEBS J 276:1266-1281. CrossRef Medline

Wang HW, Pasternak JF, Kuo H, Ristic H, Lambert MP, Chromy B, Viola KL, Klein WL, Stine WB, Krafft GA, Trommer BL (2002) Soluble oligomers of $\beta$ amyloid $_{(1-42)}$ inhibit long-term potentiation but not long-term depression in rat dentate gyrus. Brain Res 924:133-140. CrossRef Medline

Zeng H, Guo M, Martins-Taylor K, Wang X, Zhang Z, Park JW, Zhan S, Kronenberg MS, Lichtler A, Liu HX, Chen FP, Yue L, Li XJ, Xu RH (2010) Specification of region-specific neurons including forebrain glutamatergic neurons from human induced pluripotent stem cells. PLoS One 5:e11853. CrossRef Medline 